\title{
TERAPIA FOTOdinÂmiCa ANTIMICROBIANA No TRATAMENTo Endodôntico em Dentes de Cães com lesão Periapical Induzida - Análise HistopatológICA E IMUNOHISTOQUÍMICA
}

Tese de Doutorado apresentada à Faculdade de Odontologia de Ribeirão Preto da Universidade de São Paulo para a obtenção do título de Doutor em Ciências. Programa: Odontopediatria.

Área de Concentração: Odontopediatria.

Orientadora: Profa. Dra. Raquel Assed B. Segato Co-Orientador: Prof. Dr. Paulo Nelson Filho 


\section{AutorizaÇÃo PARA ReProduÇÃo}

Autorizo a reprodução e divulgação total ou parcial deste trabalho, por qualquer meio convencional ou eletrônico para fins de estudo e pesquisa, desde que citada a fonte.

\section{ZOBÉLIA MARIA DE SOUZA LOPES}

\section{Ficha Catalográfica}

Lopes, Zobélia Maria de Souza

Terapia Fotodinâmica Antimicrobiana no Tratamento Endodôntico em Dentes de Cães com Lesão Periapical Induzida - Análise Histopatológica e Imunohistoquímica. Ribeirão Preto, 2018.

82p. : il. ; $30 \mathrm{~cm}$

Tese de Doutorado apresentada à Faculdade de Odontologia de Ribeirão Preto da Universidade de São Paulo (FORP-USP) - Área de concentração: Odontopediatria.

Orientadora: Profa. Dra. Raquel Assed Bezerra Segato

Co-Orientador: Prof. Dr. Paulo Nelson Filho

1. Terapia fotodinâmica antimicrobiana 2. aPDT 3. Lesão periapical

4. Hidróxido de cálcio. 
Lopes ZMS. Terapia Fotodinâmica Antimicrobiana no Tratamento Endodôntico em Dentes de Cães com Lesão Periapical Induzida - Análise Histopatológica e Imunohistoquímica.

\author{
Tese de Doutorado apresentada à \\ Faculdade de Odontologia de Ribeirão \\ Preto da Universidade de São Paulo para a \\ obtenção do título de Doutor em Ciências \\ Programa: Odontopediatria. \\ Área de Concentração: Odontopediatria.
}

Data da defesa:

BANCA EXAMINADORA

$\operatorname{Prof}(a) \cdot \operatorname{Dr}(a)$ :

Julgamento: Assinatura:

$\operatorname{Prof}(a) \cdot \operatorname{Dr}(a)$ :

Julgamento: Assinatura:

$\operatorname{Prof}(a) \cdot \operatorname{Dr}(a)$ :

Julgamento: Assinatura:

Profa. Dra. Raquel Assed Bezerra Segato

Orientadora e Presidente da Banca Examinadora Assinatura: 



\title{
ZOBÉLIA MARIA DE SOUZA LOPES
}

\author{
Dados Curriculares
}

1973 - 1976 Graduação em Odontologia.

Universidade Federal do Amazonas, UFAM, Brasil

1982 - 1982 Especialização em Prótese Dental.

Universidade Federal do Ceará, UFC, Brasil.

1986 - 1986 Especialização em Administração Hospitalar.

Universidade de Ribeirão Preto, UNAERP, Brasil.

1996 - 1996 Aperfeiçoamento em Endodontia.

Associação Brasileira de Odontologia - Seção Amazonas.

1996 - 1997 Aperfeiçoamento em Ortodontia Preventiva.

Associação Brasileira de Odontologia - Seção Amazonas.

1996 - 1998 Aperfeiçoamento em Prótese Dentária.

Associação Brasileira de Odontologia - Seção Amazonas.

1997 - 1999 Especialização em Ortodontia e Ortopedia Facial.

Associação Brasileira de Odontologia - Seção Amazonas

2016-2018 Curso de Pós-Graduação em Odontopediatria - Doutorado (DINTER) 



\section{DEDICATÓRIA}

Dedico ao meu pai Adalberto Pessoa Lopes (in mempriam) e à minha Mãe Olinda de Souza Lopes, ao meu esposo Tadeu e ao meu filho Luâ, pelo amor incondicional e incentivo para a conclusão desse curso. 



\section{AGradecimentos Especials}

À Profa. Dra. Raquel Assed Bezerra Segato, minha querida orientadora, por estar sempre disposta a ajudar na elaboração do meu trabalho e na motivação de vida, contribuindo para o meu crescimento na docência, o que me incentiva e serve de inspiração para ajudar na formação de outros profissionais do meu estado.

À Profa. Dra. Léa Assed Bezerra da Silva, pela oportunidade da realização do dinter usp/iaes, pela amizade, carinho, dedicação e commpreensão, conhecê-la há mais de 20 anos foi muito importante para toda minha família.

Ao Prof. Dr. Paulo Nelson Filho, pela valorosa dedicação e contribuição na formação de todos os participantes do dinter. 



\section{Agradecimentos}

À Universidade de São Paulo, na pessoa do atual Reitor, Prof. Dr. Vahan Agopyan, e do Vice-reitor, Prof. Dr. Antonio Carlos Hernandes.

À Faculdade de Odontologia de Ribeirão Preto da Universidade de São Paulo, na pessoa da Diretora, Profa. Dra. Léa Assed Bezerra da Silva, e do Vice-Diretor, Prof. Dr. Arthur Belém Novaes Jūnior.

À Coordenação do curso de Pós-Graduação em Odontopediatria da Faculdade de Odontologia de Ribeirão Preto da Universidade de São Paulo, na pessoa da Coordenadora, Profa. Dra. Raquel Assed Bezerra Segato, e da Vice-Coordenadora, Profa. Dra. Léa Assed Bezerra da Silva.

Aos Professores do Departamento de Clínica Infantil da FORP/USP, Profa. Dra. Aldevina Campos de Freitas, Profa. Dra. Alexandra Mussolino de Queiroz, Profa. Dra. Andiara De Rossi Daldegan, Prof. Dr. Fabio Lourenço Romano, Prof. Dr. Francisco Wanderley Garcia de Paula e Silva, Prof. Dr. Fabrício Kitazono de Carvalho, Profa. Dra. Kranya Victoria Díaz Serrano, Profa. Dra. Léa Assed Bezerra da Silva, Profa. Dra. Maria Bernadete Sasso Stuani, Profa. Dra. Maria Cristina Borsato, Profa. Dra. Maria da Conceição Pereira Saraiva, Profa. Dra. Mirian Aiko Nakane Matsumoto, Prof. Dr. Paulo Nelson Filho, Profa. Dra. Raquel Assed Bezerra Segato e Prof. Dr. José Tarcísio Lima Ferreira.

Aos funcionários do Departamento da Clínica Infantil, Dra. Carolina Paes Torres Mantovani, Fátima Aparecida Jacinto Daniel, Fătima Rizoli, Filomena Leli Placciti, , Marco Antônio dos Santos, Dra. Marîlia Pacífico Lucisano, Matheus Morelli Zanela, Micheli Cristina Leite Rovanholo e Nilza Letícia Magalhães. 
Aos alunos do Doutorado InterInstitucional (DINTER) da Faculdade de Odontologia de Ribeirão Preto da Universidade de São Paulo e o Instituto Amazônia de Ensino Superior.

Ao Prof. Dr. Alberto Consolaro e à Profa. Dra. Erika Calvano Kuchler, docentes do Programa de Pós-Graduacão em Odontopediatria da FORP/USP.

Às alunas do Programa de Pós-Graduação em Odontopediatria da FORP/USP, Carolina Maschietto Pucinelli e Priscilla Coutinho Romualdo.

À Coordenação de Aperfeiçoamento de Pessoal de Nivel Superior (CAPES) pelo apoio. 
RESUMO

Lopes, ZMS. Terapia fotodinâmica antimicrobiana no tratamento endodôntico em dentes de cães com lesão periapical induzida - análise histopatológica e imunohistoquímica. Ribeirão Preto, 2018. 82p. Tese [doutorado]. Faculdade de Odontologia de Ribeirão Preto, Universidade de São Paulo.

Objetivo: Avaliar, in vivo, o efeito do tratamento endodôntico em sessão única utilizando a Terapia Fotodinâmica Antimicrobiana (aPDT) no reparo de lesões periapicais induzidas em dentes de cães, por meio da avaliação histopatológica e imunohistoquímica da angiogênese e de marcadores de formação óssea. $O$ tratamento endodôntico em duas sessões com curativo de demora à base de hidróxido de cálcio $(\mathrm{CH})$ foi utilizado como controle. Métodos: Lesões periapicais foram induzidas em 48 pré-molares superiores e inferiores de 6 cães, com 12 meses de idade. Após instrumentação dos canais radiculares, os dentes foram divididos, aleatoriamente, em 4 grupos: $\mathrm{CH} / 120$ dias (d) e $\mathrm{CH} / 180$ dias (d): canais radiculares preenchidos com curativo à base de $\mathrm{CH}$; $\mathrm{aPDT} / 120 \mathrm{~d}$ e aPDT/180d: canais radiculares condicionados com fotossensibilizador à base de fenotiazina $(10 \mathrm{mg} / \mathrm{mL})$, por 1 minuto e irradiados com laser de diodo em toda a extensão dos canais, conforme as recomendações do fabricante. Em seguida, todos os canais radiculares foram obturados com cimento AH Plus e, após 120 ou 180 dias, os animais foram eutanasiados e os blocos contendo dentes e tecido ósseo foram submetidos ao processamento histotécnico e à coloração de hematoxilina e eosina (HE) para a análise descritiva da região periapical e mensuração das lesões periapicais, em microscopia convencional, e contagem de vasos sanguíneos sob luz convencional e no modo fluorescente. A análise imunohistoquímica foi realizada para avaliação dos marcadores da formação óssea osteopontina (OPN) e fosfatase alcalina (ALP). Os dados obtidos foram analisados estatisticamente utilizando os testes two-way ANOVA e qui-quadrado, com nível de significância de 5\%. Resultados: Aos 120 dias, os dentes do grupo $\mathrm{CH} / 120 \mathrm{~d}$ apresentaram processo de reparo avançado, com ligamento periodontal apenas ligeiramente aumentado, presença abundante de fibras colágenas e escassas células inflamatórias. Os dentes do grupo aPDT/120d apresentaram o ligamento periodontal moderadamente aumentado e o infiltrado inflamatório era moderado. Poucas fibras colágenas foram observadas. Aos 180 dias, o mesmo padrão foi observado. As lesões periapicais nos grupos tratados com curativo à base de hidróxido de cálcio foram menores que as lesões nos grupos tratados com aPDT $(p<0,001)$, e apresentaram maior número de vasos sanguíneos $(p<0,0001)$, independentemente dos períodos de avaliação. Além disso, os dentes dos grupos tratados com pasta à base de hidróxido de cálcio apresentaram imunomarcação significativamente mais intensa para ALP e OPN $(p<0,001)$, em ambos os períodos. Conclusões: Embora o tratamento com a aPDT tenha estimulado 
a angiogênese e a expressão dos marcadores da formação óssea, o tratamento endodôntico realizado em duas sessões empregando curativo à base de hidróxido de cálcio estimulou mais intensamente esses processos e promoveu melhor reparo das lesões periapicais.

Palavras-chave: Terapia fotodinâmica antimicrobiana; aPDT; Lesão periapical; Hidróxido de cálcio. 
Lopes, ZMS. Antimicrobial Photodynamic Therapy for endodontic treatment in dog's teeth with induced apical periodontitis - Histopathologic and Imunohistochemistry analysis. Ribeirão Preto, 2018. 82p. Tese [doutorado]. Faculdade de Odontologia de Ribeirão Preto, Universidade de São Paulo.

Aim: The aim of this study was to evaluate the in vivo effect of one-session endodontic treatment with antimicrobial photodynamic therapy (aPDT) in the repair of apical periodontitis, in dogs' teeth, by histopathologic evaluation and imunohistochemistry for angiogenesis and bone formation markers. Two-session treatment with a calcium hydroxide $(\mathrm{CH})$ dressing was used as control. Methods: Apical periodontitis were induced in 48 upper and lower premolars of six 12-monthold dogs. After root canals instrumentation, teeth were randomly divided into 4 groups: $\mathrm{CH} / 120$ days (d) and $\mathrm{CH} / 180$ days (d): root canals filled with $\mathrm{CH}$-based dressing; aPDT/120d and aPDT/180d: root canals conditioned with phenothiazinebased photosensitizer $(10 \mathrm{mg} / \mathrm{mL})$ for 1 minute and irradiated with diode laser throughout the canals and according to the manufacturer's recommendations. Root canals were filled with AH Plus cement, and after 120 or 180 days, the animals were euthanized and teeth were submitted to histotechnical processing and HE staining for description of the periapical region and measurement of apical periodontitis in conventional microscopy and for counting blood vessels under conventional and fluorescent microscopy. Immunohistochemical analysis was performed to evaluate the bone formation markers osteopontin (OPN) and alkaline phosphatase (ALP). Data were statistically analyzed using two-way ANOVA and chi-square test with a significance level of 5\%. Results: At 120 days, teeth in Group $\mathrm{CH} / 120$ d presented the periodontal ligament only slightly enlarged with advanced repair and abundant collagen fibers. Inflammatory cells were scarce. Teeth in group aPDT/120d presented the periodontal ligament moderately enlarged and the inflammatory infiltrate was moderate. Few collagen fibers were observed. At 180 days, the same pattern was observed. Apical periodontitis in $\mathrm{CH}$-treated groups were smaller than the lesions in aPDT-treated groups $(p<0.001)$ and had a greater number of blood vessels ( $p$ $<0.0001$ ), regardless of evaluation periods. The teeth treated with calcium hydroxide showed significantly more intense immunostaining for ALP and OPN $(p<0.001)$, in both periods. Conclusions: Although aPDT has stimulated angiogenesis and the expression of bone formation markers, the two-session endodontic treatment with a calcium hydroxide-based dressing stimulates them more intensely and promoted better apical periodontitis repair.

Key words: Photodynamic therapy; aPDT; Apical periodontitis; Calcium hydroxide. 

SUMÁRIO

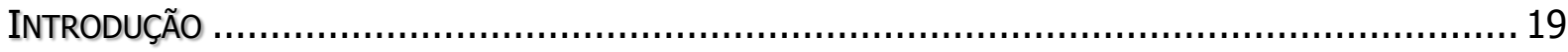

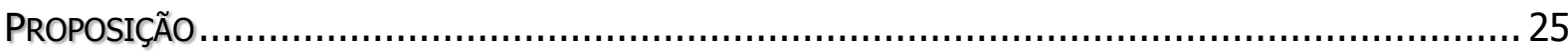

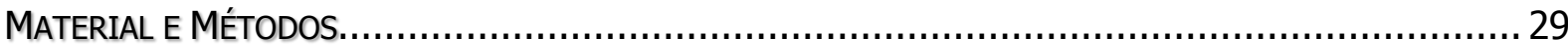

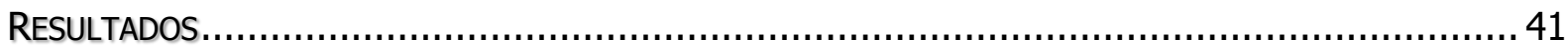

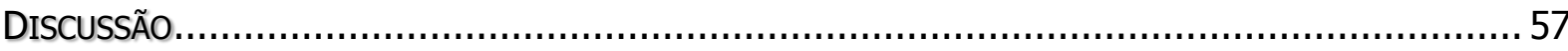

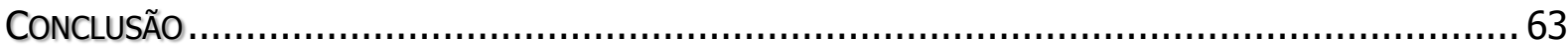

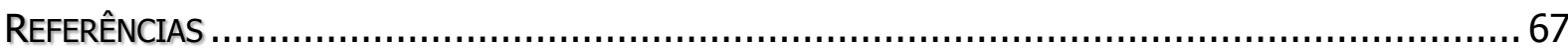

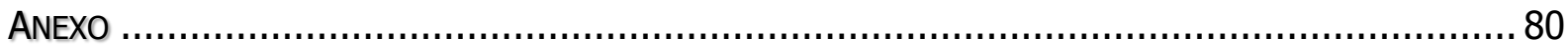






\section{INTRODUÇÃO}

O sucesso do tratamento endodôntico depende de muitos fatores e pode ser dificultado pela anatomia complexa dos canais radiculares, incluindo o número, a curvatura e as ramificações dos canais, além da localização do forame apical. Esses fatores dificultam a limpeza completa do sistema de canais radiculares (Peters, 2004; Estrela et al., 2014; Ahmad e Alenezi, 2016; Ahmed e Hashem, 2016; Hidalgo et al., 2017). Além disso, a presença de lesão periapical crônica, como consequência de infecção bacteriana proveniente da polpa dentária necrótica, está associada a uma maior taxa de insucesso após o tratamento endodôntico (Estrela et al., 2014; Hidalgo et al., 2016; Silva et al., 2017). Portanto, recomenda-se que uma medicação intracanal seja utilizada, entre as sessões, para auxiliar na desinfecção do sistema de canais radiculares, durante o tratamento endodôntico de dentes com lesão periapical. As taxas de sucesso nesses casos são maiores com o uso de uma medicação intracanal antimicrobiana entre as sessões, em comparação ao tratamento efetuado em sessão única (Vera et al., 2012; Borsatto et al., 2016; Hidalgo et al., 2016; Silva et al., 2017).

O hidróxido de cálcio tem sido a medicação intracanal mais estudada, discutida e empregada tendo em vista suas excelentes propriedades, tais como ação antimicrobiana (Assed et al., 1996; Leonardo et al., 2000; Sangalli et al., 2018), antiexsudativa (Heithersay, 1970; Allard et al., 1987; Sousa et al., 2014), indutora da formação de tecido mineralizado (Schroder, 1985; Leonardo et al., 2006; Da Silva et al., 2008; Silva et al., 2010; Nowicka et al., 2015; Hidalgo et al., 2016; Silva et al., 2017; Didilescu et al., 2018), além de apresentar biocompatibilidade (Nelson-Filho et al., 1999; Leonardo et al., 2006; Andolfatto et al., 2012; Lima et al., 2015; Zarei et al., 2016; Cintra et al., 2017), propriedade de dissolução de tecidos necróticos (Hasselgren et al., 1988; Andersen et al., 1992; Türkün et al., 1997; Zehnderet al., 2003; Slutzky-Goldberg et al., 2013), e de hidrólise do LPS bacteriano in vitro e in vivo (Safavi e Nichols, 1994; Barthel et al., 1997; Nelson-Filho et al., 2002; Silva et al., 2002; Tanomaru et al., 2003; Oliveira et al., 2005, 2007; Adl et al., 2015; Marinho et al., 2018), tornando-o a medicação intracanal de escolha durante o tratamento endodôntico (Holland et al., 2017). Para que o hidróxido de cálcio exerça 
essas funções em todo o sistema de canais radiculares este deverá permanecer, no interior dos canais radiculares, por no mínimo 14 dias, o que exigirá, portanto, a realização de duas ou mais sessões de tratamento (Spangberg et al., 2001; Leonardo et al., 2006). Há, ainda, estudos clínicos comprovando que o curativo intracanal com pasta à base de hidróxido de cálcio é necessário em casos de dentes com lesão periapical, previamente à obturação final dos canais radiculares (De Castro Rizzi-Maia et al., 2016; Silva et al., 2017).

Entretanto, na literatura específica há uma divergência crescente com relação à necessidade de múltiplas sessões durante o tratamento endodôntico, uma vez que estudos clínicos e radiográficos não relataram diferenças significativas entre os tratamentos realizados em sessão única ou em múltiplas sessões (Bharuka e Mandroli, 2016; Chhabra et al., 2017; Moreira et al., 2017). Assim, o tratamento endodôntico realizado em sessão única tornou-se uma prática comum uma vez que oferece algumas vantagens, tais como boa aceitação pelo paciente e considerações práticas relacionadas ao gerenciamento da clínica odontológica especialmente devido ao menor número de sessões que implica em menor custo e maior conforto ao paciente (Dorasani et al., 2013; Eyuboglu et al., 2017; Fonzar et al., 2017; Eppa et al., 2018).

Atualmente, a busca por alternativas complementares ao tratamento endodôntico, almejando alcançar uma taxa de sucesso comparável ou superior ao uso de medicação intracanal à base de hidróxido de cálcio, entre as sessões. Assim, diferentes materiais e técnicas vêm sendo sugeridos na literatura específica como as pastas antibióticas (Adl et al., 2012, 2014; Pai et al., 2014, Lakhani et al., 2017; Arruda et al., 2018), a associação do hidróxido de cálcio com agentes antimicrobianos como a clorexidina (De Rossi et al., 2005; Silva et al., 2008, 2009; Ito et al., 2011; Donyavi et al., 2016; Silva et al., 2017; Arruda et al., 2018), medicações baseadas em agentes naturais como a epigalogatequina-3-galato derivada do chá verde (Lee et al., 2009; Ferreira 2013; Hong et al., 2015; Ramezanali et al., 2016), novos sistemas de irrigação por pressão negativa como 0 EndoVac (Pawar et al., 2012; Cohenca et al., 2013, 2015; Pucinelli et al., 2017; Widjiastuti et al., 2018), ou passiva como EndoActivator (Huffaker et al., 2010; Paiva et al., 2013; Ramamoorthi et al., 2015; Chaudhry et al., 2017) e a Terapia 
Fotodinâmica (Silva et al., 2012; Gursoy et al., 2013; Chrepa et al., 2014; Trindade et al., 2015; Chiniforush et al., 2016; Diogo et al., 2017; Trindade et al., 2017) com diferentes níveis de eficácia.

Tradicionalmente, a Terapia Fotodinâmica (PDT) foi desenvolvida como uma abordagem alternativa para o tratamento de tumores (Dougherty, 1985; Carrera et al., 2016). É caracterizada pela destruição das células por necrose ou apoptose e pode ser utilizada para a destruição localizada de um tecido com crescimento anormal. Portanto, outras doenças infecciosas que têm em comum a característica de proliferação celular descontrolada e a presença de micro-organismos indesejáveis podem ser tratadas pela PDT, que neste caso é chamada de Terapia Fotodinâmica Antimicrobiana (aPDT) (Huang et al., 2010; Cieplik et al., 2014; Carrera et al., 2016).

O tratamento realizado com a aPDT envolve a aplicação de um fotossensibilizador (corante), seguida pela aplicação de uma fonte de luz (laser) com um comprimento de onda adequado nos tecidos sensibilizados (Dougherty et al., 1998). Esse processo gera uma reação tóxica nas células-alvo e induz a produção de oxigênio altamente reativo, causando a morte dos micro-organismos (Wainwright, 1998; Dai et al., 2009; De Oliveira et al., 2014). Atualmente, a aPDT é considerada como uma terapia complementar aos protocolos convencionais utilizados para a desinfecção do sistema de canais radiculares (Mohammadi et al., 2017).

Os fotossensibilizadores apresentam um alto grau de seletividade aos microorganismos, em relação às células do hospedeiro (Maisch et al., 2005) e a utilização do laser de baixa intensidade permite diferenciar os tecidos do hospedeiro dos microorganismos. O uso do laser ou do fotossensibilizador isoladamente não são tóxicos (Takasaki et al., 2009) e, após a aplicação do laser, apenas as células microbianas que captaram o fotossensibilizador são afetadas pelo tratamento (Vahabi et al., 2011). Portanto, trata-se de uma alternativa para direcionar o tratamento diretamente contra os micro-organismos presentes apenas no local da infecção, superando os problemas associados aos antimicrobianos (Raghavendra et al., 2009). Assim, o uso da aPDT permite alcançar seletividade, visando atingir sítios específicos da cavidade bucal.

Além disso, os fotossensibilizadores são classificados de acordo com 0 comprimento de onda que é capaz de ativá-los. Os que são ativados pela luz com 
comprimento de onda de $405 \mathrm{~nm}$ apresentam menor poder de penetração, sendo utilizados em lesões superficiais (Profio e Doiron, 1987). Por outro lado, os fotossensibilizadores da família das fenotiazinas são ativados com comprimento de onda de 620 a 700nm e apresentam maior poder de penetração. Portanto, são os mais indicados na Odontologia especialmente para o tratamento de infecções periodontais (Kömerik et al., 2002; Novaes et al., 2012; Andrade et al., 2013; Queiroz et al., 2015; de Oliveira et al., 2016; Ramos et al., 2016; Martins et al., 2017).

A Terapia Fotodinâmica Antimicrobiana é uma alternativa que foi recentemente introduzida na Endodontia e tem sido considerada como um tratamento promissor (Silva et al., 2012; Gursoy et al., 2013; Chrepa et al., 2014; Trindade et al., 2015; Garcez et al., 2016; Chiniforush et al., 2016; Hidalgo et al., 2016; Oliveira, 2016; Diogo et al., 2017; Trindade et al., 2017).

Estudos in vitro e in vivo, avaliando o efeito antimicrobiano da aPDT, demonstraram que esta terapia é capaz de reduzir o número de micro-organismos (Kömerik et al., 2003; Hayek et al., 2005; Novaes et al., 2012; Fekrazad et al., 2017; Fumes et al., 2018). Além disso, alguns estudos in vivo, por meio de análise microscópica, demonstraram a eficácia da aPDT no tratamento endodôntico de dentes com lesão periapical (Silva et al., 2012, Juric et al., 2014, Hidalgo et al., 2016, Borsatto et al., 2016, Trindade et al., 2017).

No entanto, ainda não existem evidências científicas suficientes para indicar com segurança o uso clínico da aPDT, em substituição ao tratamento endodôntico convencional (Hidalgo et al., 2016). Além disso, não existem estudos na literatura específica investigando a participação de mediadores da formação óssea no reparo periapical, após o tratamento endodôntico associado ao uso da aPDT. 
Proposição 



\section{ProposiçÃo}

O objetivo do presente estudo foi avaliar, in vivo, o efeito do tratamento endodôntico realizado em sessão única empregando a aPDT no reparo de lesões periapicais, em comparação ao tratamento endodôntico realizado em duas sessões utilizando um curativo de demora à base de hidróxido de cálcio, por meio da avaliação histopatológica e imunohistoquímica da angiogênese e de marcadores da formação óssea, em dentes de cães. 

$M_{\text {ateriale }} M_{\text {étodos }}$ 



\section{Material e Métodos}

O presente estudo foi submetido à apreciação pelo Comitê de Ética em Pesquisa Animal da Faculdade de Odontologia de Bauru, Universidade de São Paulo Brasil, tendo sido aprovado (processo número 19/2012 - ANEXO A). Os cuidados com o bem-estar dos animais de experimentação seguiram as Normas e Princípios Éticos adotados pela CEUA/FORP e as Resoluções Normativas do Conselho Nacional de Controle de Experimentação Animal (CONCEA), regulamentadas pela Constituição Federal Brasileira na Lei no 11.794 de 8 de outubro de 2008. Todos os procedimentos seguiram as normas e princípios éticos preconizados pela instituição.

\section{Procedimentos Operatórios}

O protocolo experimental foi realizado com base nas normas da International Organization for Standardization (ISO) no 7405:2008.

Foram utilizados os $2^{\text {os }}$ e $3^{\text {os }}$ pré-molares superiores e os $2^{\text {os }}, 3^{\text {os }}$ e $4^{\text {os }}$ prémolares inferiores permanentes de 6 cães, provenientes de uma mesma ninhada e sem raça definida, com 12 meses de idade e pesando, em média, 15 quilos. Os animais foram adquiridos do Biotério Central da Universidade Federal de Santa Catarina - Brasil. Durante todo o experimento, os animais foram mantidos no Biotério II da Faculdade de Odontologia de Ribeirão Preto, Universidade de São Paulo Brasil, alojados em baias individuais, com livre acesso à água e ração, sob o supervisionamento diário de um médico veterinário experiente. Previamente ao início do experimento, os animais receberam vermífugos (Drontal Puppy - Bayer, São Paulo, SP, Brasil), na dosagem de 1 comprimido a cada $10 \mathrm{Kg}$ de peso do animal, vitaminas (Glicopan Pet - Vetnil Indústria e Comérico de Produtos Veterinários Ltda., Louveira, SP, Brasil), vacina antirrábica (Rai-Vac I - Fort Dodge, Campinas, SP, Brasil) e a vacina Duramune (Fort Dodge) em 3 doses, com 3 semanas de intervalo entre cada aplicação.

Um total de 48 dentes (96 raízes) foi distribuído em 4 grupos, conforme descrito na Tabela 1. Para que todas as variáveis fossem testadas em um mesmo animal, em diferentes quadrantes, cada hemiarco recebeu um material em sistema de rodízio, distribuído ao acaso. Todo instrumental utilizado nos procedimentos 
operatórios foi esterilizado em autoclave a $121^{\circ} \mathrm{C}$, por 20 minutos. Além disso, todos os procedimentos foram realizados por um único cirurgião-dentista com ampla experiência em experimentação animal.

\begin{tabular}{|c|c|c|c|}
\hline GRUPOS & TRATAMENTOS & $\begin{array}{l}\text { PERÍODO } \\
\text { EXPERIMENTAL }\end{array}$ & $\begin{array}{l}\text { NO DE DENTES } \\
\text { (RAÍZES) }\end{array}$ \\
\hline $\mathrm{CH} / 120 \mathrm{~d}$ & $\begin{array}{l}\text { Tratamento endodôntico em duas } \\
\text { sessões, empregando o curativo de } \\
\text { demora à base de hidróxido de cálcio }\end{array}$ & 120 dias & $12(24)$ \\
\hline aPDT/120d & $\begin{array}{l}\text { Tratamento endodôntico em uma } \\
\text { única sessão, empregando a aPDT }\end{array}$ & 120 dias & $12(24)$ \\
\hline $\mathrm{CH} / 180 \mathrm{~d}$ & $\begin{array}{l}\text { Tratamento endodôntico em duas } \\
\text { sessões, empregando o curativo de } \\
\text { demora à base de hidróxido de cálcio }\end{array}$ & 180 dias & $12(24)$ \\
\hline aPDT/180d & $\begin{array}{l}\text { Tratamento endodôntico em uma } \\
\text { única sessão, empregando a aPDT }\end{array}$ & 180 dias & $12(24)$ \\
\hline
\end{tabular}

Os animais foram pré-anestesiados por meio de injeção endovenosa de Neozine (Aventis Pharma Ltda, Suzano, SP, Brasil), na concentração de $1 \mathrm{mg} / \mathrm{kg}$ de peso, 15 minutos previamente à realização dos procedimentos operatórios. Em seguida, foi realizada a indução da anestesia com Zoletil ${ }^{\circledR} 50$ (Virbac do Brasil, São Paulo, SP, Brasil), na dosagem de $0,1 \mathrm{~mL} / \mathrm{kg}$ de peso, por via endovenosa, para facilitar a passagem da sonda endotraqueal, necessária para a realização da anestesia inalatória. Então, a manutenção da anestesia foi realizada com Isoflurano (Abbott Laborat. do Brasil Ltda., Rio de Janeiro, RJ, Brasil), utilizando o aparelho para anestesia inalatória Takaoka KT-20 (Takaoka Ind. e Com., São Paulo, SP, Brasil). Durante todo o procedimento operatório, os animais foram mantidos com solução isotônica de cloreto de sódio a 0,9\% (Glicolabor Industria Farmacêutica Ltda., Ribeirão Preto, SP, Brasil) e permaneceram sob monitoramento cardiorrespiratório realizado com o auxílio de um oxímetro de pulso veterinário (Edan ZEH100B, Sistem Biomédica, Yucatan, México).

Radiografias periapicais de todos os dentes utilizados no presente estudo foram realizadas para a confirmação do completo desenvolvimento radicular e da ausência de alterações como calcificações ou curvaturas radiculares muito acentuadas. Foi utilizada a técnica da bissetriz, com filmes periapicais Ultraspeed ${ }^{\circledR}$, tamanho 2 (Eastman Kodak Company, Rochester, EUA), utilizando o aparelho de 
raios-X odontológico Heliodent ${ }^{\circledR}$ (Siemens, New York, EUA), com $60 \mathrm{kVp}, 10 \mathrm{~mA}$ e tempo de exposição de 1 segundo. As radiografias foram reveladas pelo método tempo/temperatura e arquivadas em cartelas plásticas.

Previamente à indução das lesões periapicais, foi realizada profilaxia dentária para remoção de biofilme e cálculo, seguida da aplicação de digluconato de clorexidina a 0,12\% (Periogard, Colgate-Palmolive Indústria Ltda., Brasil). A seguir, foram induzidas lesões periapicais nos 48 dentes selecionados para o estudo. A abertura coronária oclusal foi realizada utilizando pontas diamantadas esféricas n 1015 (K.G. Sorensen, São Paulo, SP, Brasil) montadas em alta rotação, refrigeradas com ar e água abundante. Foram realizadas duas aberturas oclusais, uma mesial e outra distal, mantendo-se a ponte de esmalte vestíbulo-lingual, com o objetivo de prevenir fraturas coronárias.

A remoção da polpa coronária seguida da exploração dos canais radiculares com lima tipo K, n¹5 (Dentsply Maillefer, Ballaigues, Suíça). Após o descolamento da polpa radicular, foi efetuada sua remoção com uma lima Hedströen (Dentsply Maillefer, Ballaigues, Suíça). Após a remoção da polpa, os canais radiculares foram mantidos expostos ao meio bucal, durante 7 dias. Decorrido esse período, foi realizada a remoção dos resíduos da câmara pulpar com auxílio de curetas e de irrigação com água destilada, sob nova anestesia. Após secagem e colocação de uma mecha de algodão na câmara pulpar, foi realizado o selamento coronário com cimento à base de óxido de zinco e eugenol $\left(\right.$ IRM $^{\circledR}$, Dentsply Indústria e Comercio Ltda, Petrópolis, RJ, Brasil) para que pudesse se estabelecer um ambiente de anaerobiose (Leonardo et al., 1993).

$\bigcirc$ analgésico Cloridrato de Tramadol (Anangon ${ }^{\circledR}$, Laboratórios Biosintética Ltda, São Paulo, SP, Brasil) foi administrado por via endovenosa, na dosagem de $3 \mathrm{mg} / \mathrm{Kg}$ de peso, uma vez ao dia, durante 3 dias, com o objetivo de diminuir a sensibilidade pós-operatória. Os animais foram observados diariamente por um médico veterinário, para verificar quaisquer alterações no comportamento ou na alimentação.

Radiografias periapicais foram realizadas a cada 15 dias, até que radiolucências periapicais fossem observadas, o que ocorreu aproximadamente após 45 dias da realização do selamento provisório. 
Após as lesões periapicais serem observadas nas radiografias, os dentes foram novamente isolados com dique de borracha e o campo operatório submetido à antissepsia com gluconato de clorexidina a 2,0\%. O cimento provisório e a mecha de algodão da câmara pulpar foram, então, removidos e os canais radiculares submetidos à neutralização do conteúdo séptico-tóxico, aplicando o princípio coroa/ápice (Leonardo, 2005). Foram utilizadas limas tipo K, introduzidas no canal radicular progressivamente, com diminuição gradativa dos diâmetros e acompanhadas por irrigação abundante com solução de hipoclorito de sódio a 2,5\%. Em seguida, foi realizada uma radiografia periapical, pela técnica da bissetriz, objetivando-se realizar a odontometria para a obtenção do Comprimento Real de Trabalho (CRT), estabelecido a $1 \mathrm{~mm}$ aquém do ápice radiográfico.

Determinada a odontometria, o forame apical foi alargado com limas tipo $\mathrm{K}$ de $n^{0 s} 15,20$ e 25, sendo esta última lima designada de Instrumento Apical Foraminal (IAF), para a padronização do diâmetro de abertura apical de todos os dentes. Na mesma sessão, foi realizado o preparo biomecânico, empregando instrumentos de níquel-titânio do Sistema Protaper Universal (Dentsply Maillefer), até a lima F5, no CRT. Após a utilização de cada instrumento, foi realizada irrigação/aspiração/inundação dos canais radiculares com $3,6 \mathrm{~mL}$ de solução de hipoclorito de sódio a $2,5 \%$. Terminado o preparo biomecânico, o IAF foi novamente utlizado em todo o comprimento do dente, para a remoção de possíveis raspas de dentina e resíduos acumulados na região do forame apical, em decorrência do preparo biomecânico. Então, os canais radiculares foram secos com pontas de papel absorvente esterilizadas de calibre compatível com o diâmetro do último instrumento utilizado, inundados com solução de etilenodiamino tetracético (EDTA), tamponado em pH 7,4 e agitado com uma lima até o CRT, por 3 minutos. Após irrigação copiosa com solução de hipoclorito de sódio a $1 \%$ para neutralização do EDTA, foi realizada nova secagem por aspiração e uso de pontas de papel absorvente esterilizadas no CRT e cada hemi-arco de cada animal foi submetido, aleatoriamente, aos diferentes protocolos de tratamento, a fim de testar todas as variáveis no mesmo animal.

Os quatro grupos foram estabelecidos de acordo com os seguintes tratamentos: 
- Grupos $\mathbf{C H} / \mathbf{1 2 0 d}$ e $\mathbf{C H} / \mathbf{1 8 0 d}$ (tratamento endodôntico realizado um duas sessões, empregando o curativo de demora à base de hidróxido de cálcio): Após os procedimentos de instrumentação, os canais foram preenchidos com uma pasta à base de hidróxido de cálcio (Calen ${ }^{\circledR}$, SS White Artigos Dentários Ltda., Rio de Janeiro, Brasil), utilizando uma agulha longa 27G, até o limite do ápice radiográfico. Após a colocação de uma mecha de algodão esterilizada na entrada dos canais radiculares, foi realizado o selamento coronário provisório com cimento à base de ionômero de vidro (Vidrion R, S.S. White Art. Dent. Ltda., Rio de Janeiro, Brasil), por 15 dias. Decorrido este período, o curativo foi removido dos canais, sob isolamento absoluto com dique de borracha, por sucessivas irrigações com $\mathrm{NaOCl}$ a 2,5\%, irrigação realizada com solução de EDTA, por 3 minutos, seguida de irrigação final com $\mathrm{NaOCl}$ a 2,5\%. A seguir, os canais radiculares foram secos com pontas de papel absorvente esterilizadas e obturados com o cimento AH Plus (De Trey; Dentsply, Konstanz, Alemanha) e cones de guta-percha, por condensação lateral. Após o corte do excesso da obturação e realização da condensação vertical, as câmaras pulpares foram limpas e os dentes definitivamente restaurados com uma base de cimento de ionômero de vidro e amálgama de prata (Velvalloy, S.S.White Art. Dent. Ltda., Rio de Janeiro, RJ, Brasil).

- Grupos aPDT/120d e aPDT/180d (tratamento endodôntico realizado em sessão única, empregando a aPDT): Após os procedimentos de instrumentação, os canais radiculares foram condicionados com 0 fotossensibilizador à base de fenotiazina na concentração de $10 \mathrm{mg} / \mathrm{mL}$ (Helbo Blue, Bredent medical GmbH \& Co.KG, Senden, Alemanha), com volume de $70 \mu \mathrm{L}$, durante 1 minuto. Em seguida, os canais foram irrigados com água destilada esterilizada, secos com pontas de papel esterilizadas e irradiados com um laser de diodo (Helbo Therapielaser, Helbo Photodynamic Systems Grieskirchen, Áustria) portátil, com $20 \mathrm{~mW}$ de potência, comprimento de onda de $660 \mathrm{~nm}$ e irradiância de $60 \mathrm{~mW} / \mathrm{cm}^{2}$, por meio de fibra óptica flexível com diâmetro de 0,6mm (Helbo 3D Pocket Probe, Helbo Photodynamic Systems Grieskirchen, Áustria). A área do spot da fibra foi equivalente a $0,002 \mathrm{~cm}^{2}$, a potência utilizada foi de $0,06 \mathrm{~W}$ e a energia utilizada foi $3,6 \mathrm{~J}$. Durante a 
irradiação, a fibra foi introduzida no canal radicular, no comprimento de trabalho. A fibra foi projetada para fornecer uma exposição tridimensional da área de interesse. A técnica empregada para aplicação do laser foi por meio de movimento vertical do ápice para a cervical, percorrendo $2 \mathrm{~mm}$ por segundo. $O$ fotossensibilizador foi irradiado durante 1 minuto em modo de onda contínua, conforme recomendado pelo fabricante. A fluência entregue ao fotossensibilizador foi de $1.800 \mathrm{~J} / \mathrm{cm}^{2}$. Em seguida, os canais foram irrigados com solução salina e secos com pontas de papel absorvente esterilizadas. A obturação foi realizada na mesma sessão com o cimento AH Plus e cones de guta-percha e os dentes foram definitivamente restaurados, conforme anteriormente descrito para os outros grupos.

Após o término dos procedimentos operatórios, radiografias periapicais foram realizadas e administrado aos animais um analgésico (cloridrato de tramadol), na dosagem de $3 \mathrm{mg} / \mathrm{kg}$ de peso, por via endovenosa, a cada 12 horas, durante 2 dias. Os animais foram acompanhados por um médico veterinário experiente durante todo o período experimental, com o objetivo de observar possíveis mudanças nos hábitos alimentares e desenvolvimento de processos inflamatórios, dentre outras intercorrências.

Os animais foram eutanasiados após 120 dias (grupos $\mathrm{CH} / 120 \mathrm{~d}$ e aPDT/120d) e após 180 dias (grupos CH/180d e aPDT/180d), inicialmente por meio de anestesia com Neozine injetável, na dosagem de $1 \mathrm{mg} / \mathrm{kg}$ de peso. Após 15 minutos, foi realizada anestesia com Tiopental (Cristália, Produtos Químicos Farmacêuticos Ltda., Itapira, Brasil) endovenoso, na dosagem de $25 \mathrm{mg} / \mathrm{kg}$ de peso, injetado lentamente. Em seguida, foi efetuada a eutanásia com cloreto de potássio a $20 \%$, via endovenosa, na dosagem de $100 \mathrm{mg} / \mathrm{kg}$ de peso, também injetado lentamente.

\section{Processamento Histotécnico}

Após a eutanásia dos animais, as maxilas e as mandíbulas foram removidas, dissecadas e seccionadas com o auxílio de um bisturi, reduzidas em seu volume e lavadas em água corrente. Para facilitar o processamento histotécnico, as peças foram seccionadas utilizando discos diamantados, sob constante refrigeração com 
água, obtendo-se blocos das peças anatômicas contendo os dentes individualmente e tecidos perirradiculares adjacentes. Os blocos foram submetidos à fixação em solução de formol tamponado a 10\%, por 48 horas e à desmineralização em solução à base de EDTA a $10 \%(\mathrm{pH} \mathrm{7,4)}$. As peças foram mantidas nesta solução, à temperatura ambiente, trocada semanalmente, até sua completa desmineralização, a qual ocorreu após 60 dias, aproximadamente. 0 grau de desmineralização das estruturas foi testado por meio da penetração de uma agulha nos tecidos, para verificação da sua consistência. Após esse procedimento, as peças foram neutralizadas com solução de sulfato de sódio a 5\% (Sulfato de Sódio Anidro - J.T. Baker Fisher Sci., EUA), por 24 horas e submetidas ao processamento histotécnico de rotina, sendo lavadas em água corrente por 8 horas, desidratadas em álcoois de concentrações crescentes (70\%, 80\% e 95\% por 1 hora cada; 2 trocas de $100 \%$ por 1 hora cada e 1 troca de álcool 100\%, overnight), diafanizadas em xilol (3 banhos de 40 minutos) e incluídas em parafina (Histosec Pastillen, Merck, Darmstadt, Alemanha).

Os blocos contendo os dentes foram cortados longitudinalmente em micrótomo (Leica RM2145; Leica Microsystems GmbH, Wetzlar, Alemanha), para obtenção de cortes seriados com $5 \mu \mathrm{m}$ de espessura em toda a extensão da lesão periapical. Cortes representativos de cada grupo foram corados com hematoxilina e eosina (HE) e examinados em microscopia de luz convencional por um examinador experiente e cego com relação aos grupos.

\section{Análise Descritiva das Regiões Apical e Periapical}

Foi realizada uma análise microscópica descritiva utilizando o microscópio Axio Imager.M1 (Carl Zeiss, Jena, Alemanha) acoplado a uma câmera AxioCam MRc5 (Carl Zeiss).

A descrição das regiões apical e periapical de cada grupo foi realizada de acordo com os seguintes parâmetros histopatológicos: infiltrado inflamatório periapical (ausente, suave, moderado ou severo), espessura do ligamento periodontal apical (normal, levemente aumentada, moderadamente aumentada ou severamente aumentada) e reabsorção dos tecidos mineralizados (ausente ou presente), em microscopia de luz convencional (Hidalgo et al., 2016). 


\section{Análise Morfométrica da Área das Lesões Periapicais}

A análise morfométrica do tamanho das lesões periapicais foi realizada nos espécimes corados com $\mathrm{HE}$, em microscopia de luz convencional, usando o microscópio Axio Imager.M1 no aumento de 1,25X. A área da lesão periapical, em $\mathrm{mm}^{2}$, foi delimitada e mensurada pelo software Axio Vision Rel 4.8. A delimitação da lesão excluiu as áreas saudáveis, como o ligamento periodontal, cemento e osso alveolar, e incluiu as áreas de reabsorção e infiltrado inflamatório.

\section{Análise da Angiogênese - Contagem de Vasos Sanguíneos}

Nos espécimes corados com $\mathrm{HE}$, foi realizada a contagem do número de vasos sanguíneos presentes na região mediana da lesão adjacente ao forame apical, em uma área de aproximadamente $0,085 \mathrm{~mm}^{2}$. A análise foi realizada no aumento de 40X, sob luz convencional e no modo fluorescente, utilizando o filtro Alexa Fluor 488 (AF488), no microscópio Axio Imager.M1.

Os vasos sanguíneos foram facilmente identificados pela forte fluorescência verde claro sob luz fluorescente, evidenciando tanto a parede dos vasos, quanto os glóbulos vermelhos presentes no seu interior. Os resultados foram expressos em número de vasos sanguíneos.

\section{Análise Imunohistoquímica}

A análise imunohistoquímica foi empregada para determinar a intensidade de imunomarcação das proteínas Osteopontina (OPN) e Fosfatase Alcalina (ALP), por meio da técnica da imunoperoxidase (Silva et al., 2012).

Os cortes histológicos foram desparafinizados, sendo os epítopos antigênicos recuperados com calor utilizando tampão citrato $(\mathrm{pH}=6,0)$, em forno de micro-ondas. Após retornarem à temperatura ambiente, as lâminas foram lavadas 2 vezes por 5 minutos com PBS e 1 vez com solução PBS/Triton (Sigma-Aldrich Corporation, Saint Louis, EUA) pelo mesmo período. O bloqueio da peroxidase endógena foi realizado com peróxido de hidrogênio a 3\%, por 40 minutos. A seguir, as lâminas foram novamente lavadas com PBS e PBS/Triton, conforme descrito anteriormente. 0 bloqueio das ligações inespecíficas foi realizado com solução de 3\% BSA (albumina de soro bovino)/PBS, por 1 hora. A seguir, as lâminas foram incubadas overnight, em 
geladeira, com os anticorpos primários diluídos em BSA a 3\%: anti-OPN (rabbit polyclonal antibody, ab8448, Abcam PLC, diluído 1:150) e anti-ALP (mouse monoclonal antibody, sc-271431, Santa Cruz Biotechnology Inc., diluído 1:50).

Após retornarem à temperatura ambiente, as lâminas foram lavadas e incubadas com anticorpo secundário biotinilado (goat anti-mouse IgG-B sc-2039 e goat anti-rabbit IgG-B sc-2040; Santa Cruz Biotechnology Inc., diluídos 1:200), por 1 hora à temperatura ambiente. Depois de nova lavagem, foi colocado o complexo avidina-biotina-peroxidase ( $A B C$ kit, Vecstain; Vector Laboratories Inc.) por 30 minutos. A seguir, as lâminas foram novamente lavadas com PBS e PBS/Triton e foi efetuada a revelação da reação com solução de diaminobenzidina (DAB; SigmaAldrich Corporation, Saint Louis, EUA) e $\mathrm{H}_{2} \mathrm{O}_{2}$ a $3 \%$ em PBS, por 1 minuto. As lâminas foram contra-coradas com Hematoxilina de Harris por 10 segundos, lavadas em água corrente, lavadas em água amoniacal, por 30 segundos, lavadas em água corrente, diafanizadas, desidratadas e montadas.

Todas as análises foram realizadas por um único examinador experiente e cego com relação aos grupos avaliados.

As análises foram realizadas em microscópio Axio Imager.M1, sob luz convencional. A marcação positiva para OPN ou ALP foi avaliada por meio dos escores: 0 (ausente), 1 (suave), 2 (moderada) ou 3 (intensa).

\section{Análise Estatística}

Os dados obtidos após a avaliação morfométrica das lesões periapicais e a avaliação dos vasos sanguíneos foram analisados estatisticamente utilizando o teste two-way ANOVA. Os dados obtidos após as avaliações imunohistoquímicas foram transformados em porcentagem e analisados pelo teste qui-quadrado. Utilizou-se 0 programa estatístico Graph Pad Prism 6.0 (Graph Pad Software Inc., San Diego, CA, EUA) e o nível de significância adotado para todas as análises foi de $5 \%$. 

Resultados 



\section{RESULTADOS}

\section{Análise Descritiva das Regiões Apical e Periapical}

Aos 120 dias, a região apical (cemento) dos dentes do grupo $\mathrm{CH} / 120 \mathrm{~d}$ apresentou áreas de reabsorção reparadas, na maioria dos espécimes. O ligamento periodontal encontrava-se apenas ligeiramente aumentado, com avançado processo de reparo e presença abundante de fibras colágenas. Além disso, foi observada escassa e difusa presença de células inflamatórias. Neste mesmo período, os espécimes do grupo aPDT/120d apresentaram algumas áreas de reabsorção não reparadas no cemento apical. O ligamento periodontal encontrava-se moderadamente aumentado, com poucas fibras colágenas. $\mathrm{O}$ infiltrado inflamatório era moderado e predominantemente mononuclear. Poucas fibras colágenas foram observadas e o osso alveolar encontrava-se frequentemente desnudado. Aos 180 dias, o mesmo padrão foi observado, sem diferenças significativas entre os grupos.

A Figura 1 ilustra os eventos histopatológicos observados, após a avaliação da resposta dos tecidos apicais e periapicais nos diferentes grupos experimentais e períodos experimentais. 

Figura 1 - Eventos histopatológicos observados após a avaliação da resposta dos tecidos apicais e periapicais aos tratamentos endodônticos realizados. (A) Dente do grupo tratado com curativo à base de hidróxido de cálcio $(\mathrm{CH})$, após 120 dias: ligamento periodontal discretamente aumentado, com avançado processo de reparo, fibras colágenas abundantes e células inflamatórias escassas e difusas. (B) Maior aumento de A. (C) Dente do grupo tratado com aPDT, após 120 dias: áreas de reabsorção não reparadas, ligamento periodontal moderadamente aumentado, infiltrado inflamatório moderado e poucas fibras colágenas. (D) Maior aumento de C. (E) Grupo $\mathrm{CH} / 180 \mathrm{~d}$ com as mesmas características do grupo $\mathrm{CH} / 120$ d. (F) Maior aumento de E. (G) Grupo aPDT/180d com as mesmas características do grupo aPDT/120d. (H) Maior aumento de G.
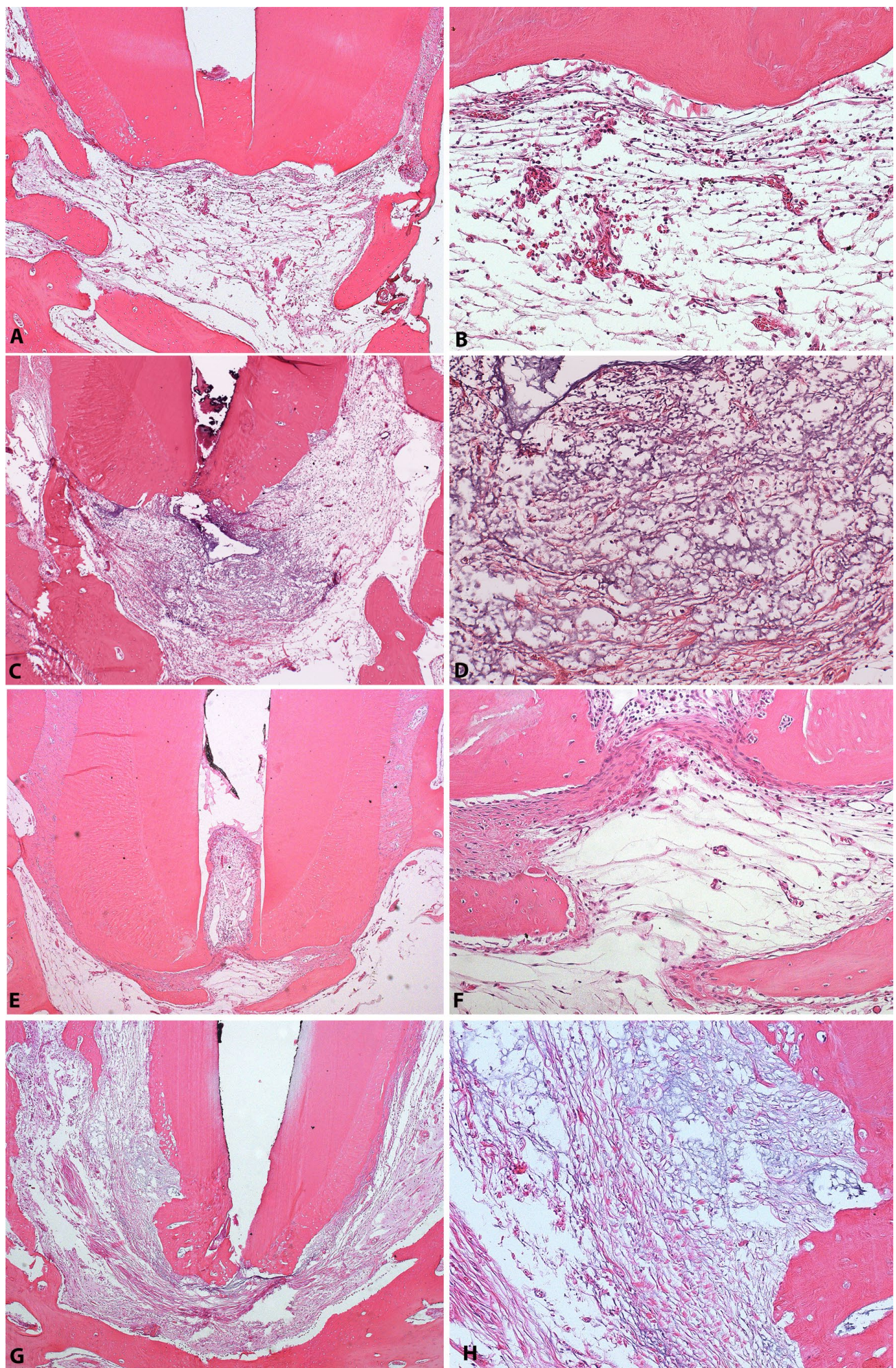



\section{Análise Morfométrica da Área das Lesões Periapicais}

As lesões periapicais dos grupos tratados com curativo à base de hidróxido de cálcio foram menores, em comparação às lesões dos grupos tratados com aPDT $(p<0,001)$, independentemente do tempo de tratamento. O efeito do tempo não foi considerado significante $(p=0,86)$. As lesões periapicais dos grupos $C H / 120 d$, aPDT/120d, CH/180d e aPDT/180d apresentaram áreas médias de 1,18 $( \pm 0,41)$, $3,29( \pm 1,07), 1,41( \pm 0,47)$ e 3,25 $( \pm 2,97) \mathrm{mm}^{2}$, respectivamente (Figura 2).

Figura 2 - Área das lesões periapicais, em $\mathrm{mm}^{2}$, após o tratamento endodôntico realizado em sessão única, empregando o curativo de demora à base de hidróxido de cálcio $(\mathrm{CH})$ em duas sessões ou a terapia fotodinâmica antimicrobiana (aPDT), após 120 ou 180 dias.

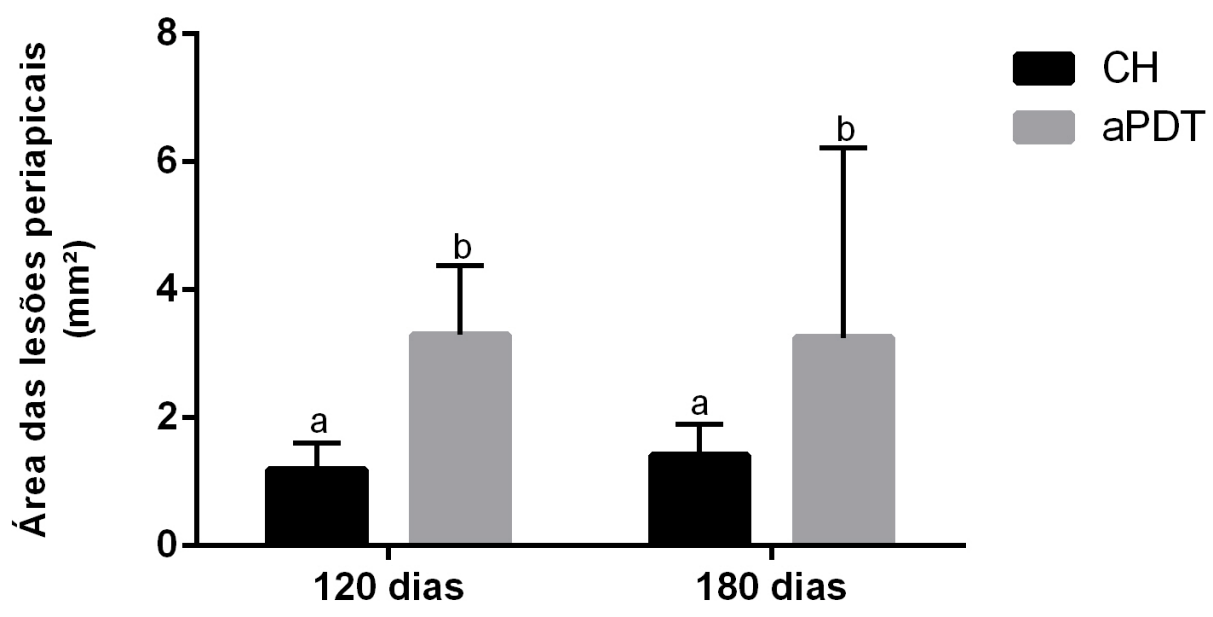

\section{Análise da Angiogênese - Contagem de Vasos Sanguíneos}

Com relação a análise do número de vasos sanguíneos (Figura 3), foi possível observar diferença estatisticamente significante entre os grupos $(p<0,0001)$, sendo que os espécimes tratados com pasta à base de hidróxido de cálcio apresentaram maior número de vasos sanguíneos, em comparação aos espécimes tratados com aPDT, independentemente do tempo de tratamento. A Figura 4 ilustra os espécimes representativos de cada grupo, em microscopia convencional e fluorescente, evidenciando os vasos sanguíneos presentes na região mediana da lesão periapical adjacente ao forame apical.

Ressalta-se que, qualitativamente, além de mais numerosos, os vasos sanguíneos dos espécimes tratados com a pasta à base de hidróxido de cálcio, 
independentemente do período de avaliação, foram mais calibrosos, maduros e volumosos, além de apresentarem paredes mais espessas e um maior número de glóbulos vermelhos no seu interior, como pode ser observado na Figura 4.

Figura 3 - Número de vasos sanguíneos presentes na região mediana da lesão periapical adjacente ao forame apical, após o tratamento endodôntico realizado em sessão única, empregando o curativo de demora à base de hidróxido de cálcio $(\mathrm{CH})$ e a terapia fotodinâmica antimicrobiana (aPDT) em duas sessões, após 120 ou 180 dias.

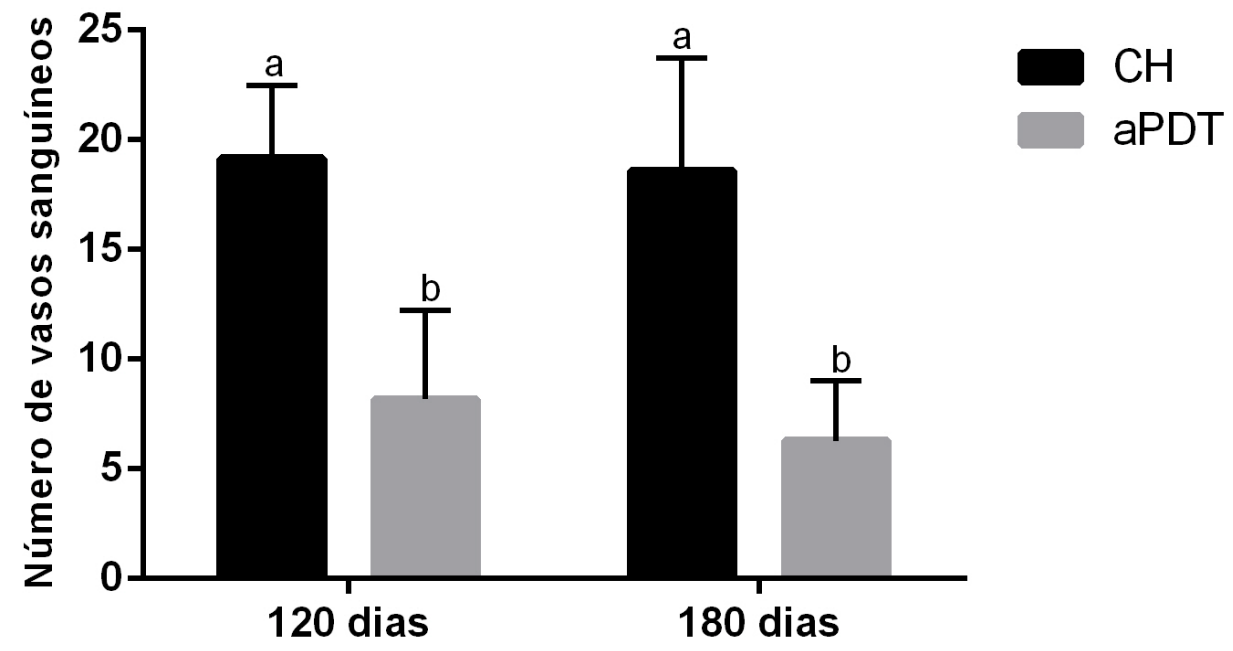


Figura 4 - Fotomicrografias representativas dos espécimes após tratamento endodôntico realizado em duas sessões, empregando um curativo de demora à base de hidróxido de cálcio $(\mathrm{CH})$, após $120(\mathrm{AB})$ e 180 dias (EF), e após tratamento endodôntico realizado em sessão única, empregando a aPDT, após $120(\mathrm{CD})$ e 180 dias $(\mathrm{GH})$, evidenciando os vasos sanguíneos presentes na região mediana da lesão periapical adjacente ao forame apical, em microscopia convencional e fluorescente.

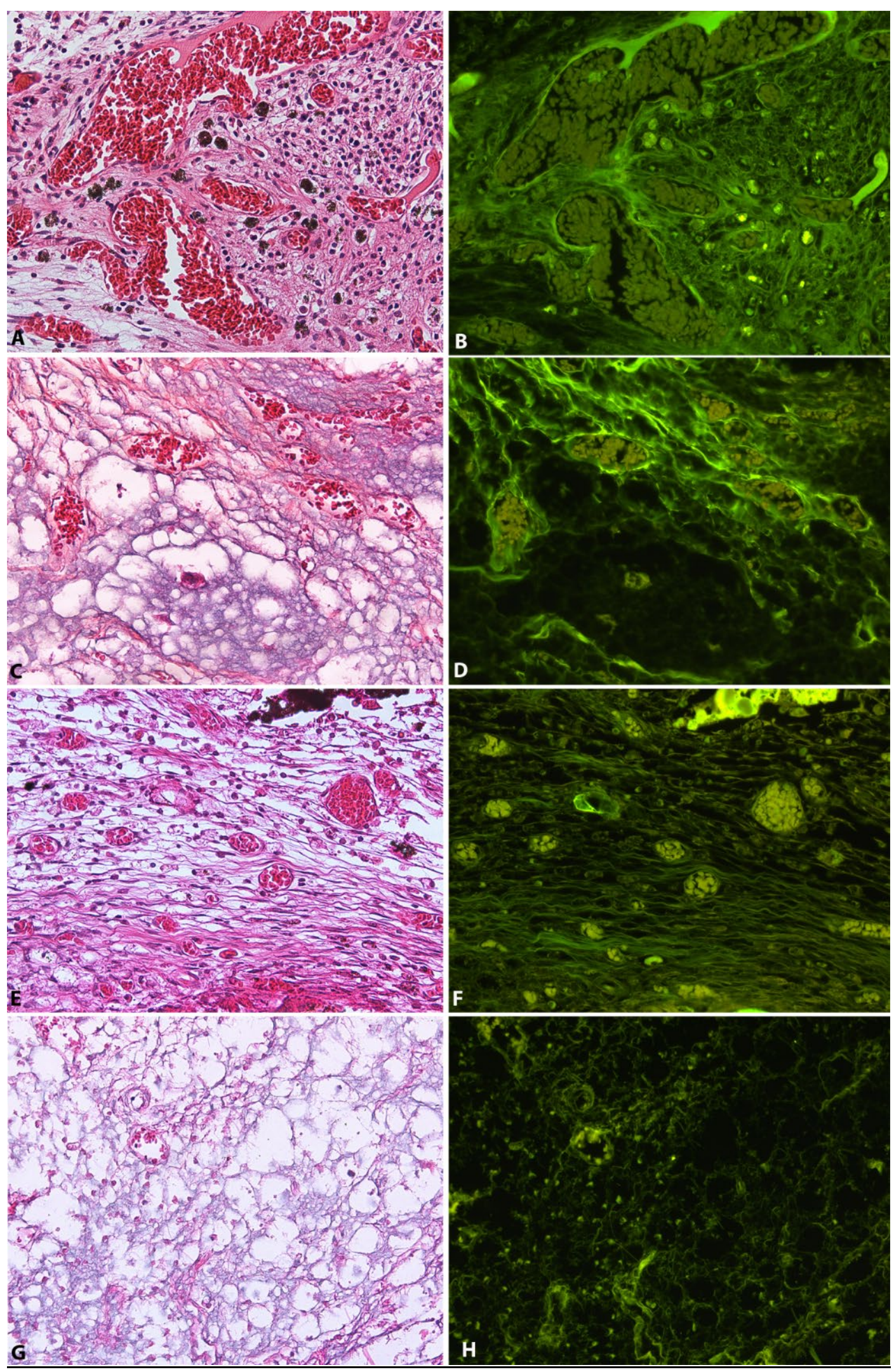





\section{Análise Imunohistoquímica}

A análise estatística após a avaliação das imunomarcações para ALP (Figura 5) revelou que o grupo tratado com curativo de demora à base de hidróxido de cálcio apresentou imunomarcação significantemente mais intensa $(p<0,001)$, em ambos os períodos, em comparação à aPDT. Em porcentagem, e considerando a intensidade da marcação como suave, moderada e intensa, obteve-se, respectivamente: $0 \%, 40 \%$ e $60 \%$ para o grupo $\mathrm{CH} / 120 \mathrm{~d} ; 20 \%$, $80 \%$ e $0 \%$ para aPDT/120d; $0 \%, 60 \%$ e $40 \%$ para $\mathrm{CH} / 180$ d e $40 \%$, 40\% e $20 \%$ para aPDT/180d.

O mesmo padrão foi observado na imunomarcação para OPN (Figura 6), com marcação mais intensa no grupo tratado com curativo de demora à base de hidróxido de cálcio $(p<0,001)$, independentemente do período, em comparação à aPDT. Em porcentagem e considerando a intensidade da marcação positiva para OPN como suave, moderada e intensa, obteve-se, respectivamente: $20 \%$, $60 \%$ e $20 \%$ para o grupo $\mathrm{CH} / 120 \mathrm{~d} ; 60 \%$, $40 \%$ e $0 \%$ para aPDT $120 \mathrm{~d} ; 20 \%, 60 \%$ e $20 \%$ para $\mathrm{CH} / 180$ d e $40 \%$, $60 \%$ e $0 \%$ para aPDT 180 d.

Resumidamente, todos os tratamentos induziram a expressão de ALP e OPN, porém, em maior intensidade nos grupos tratados com curativo à base de hidróxido de cálcio. 

Figura 5 - Fotomicrografias representativas dos espécimes após tratamento endodôntico realizado em duas sessões, empregando um curativo de demora à base de hidróxido de cálcio (CH), após 120 (AB) e 180 dias $(E F)$, e após tratamento endodôntico realizado em sessão única, empregando a aPDT, após 120 (CD) e 180 dias $(\mathrm{GH})$, demonstrando imunomarcação para fosfatase alcalina [ALP] (marrom), que foi mais intensa nos grupos tratados com $\mathrm{CH}$

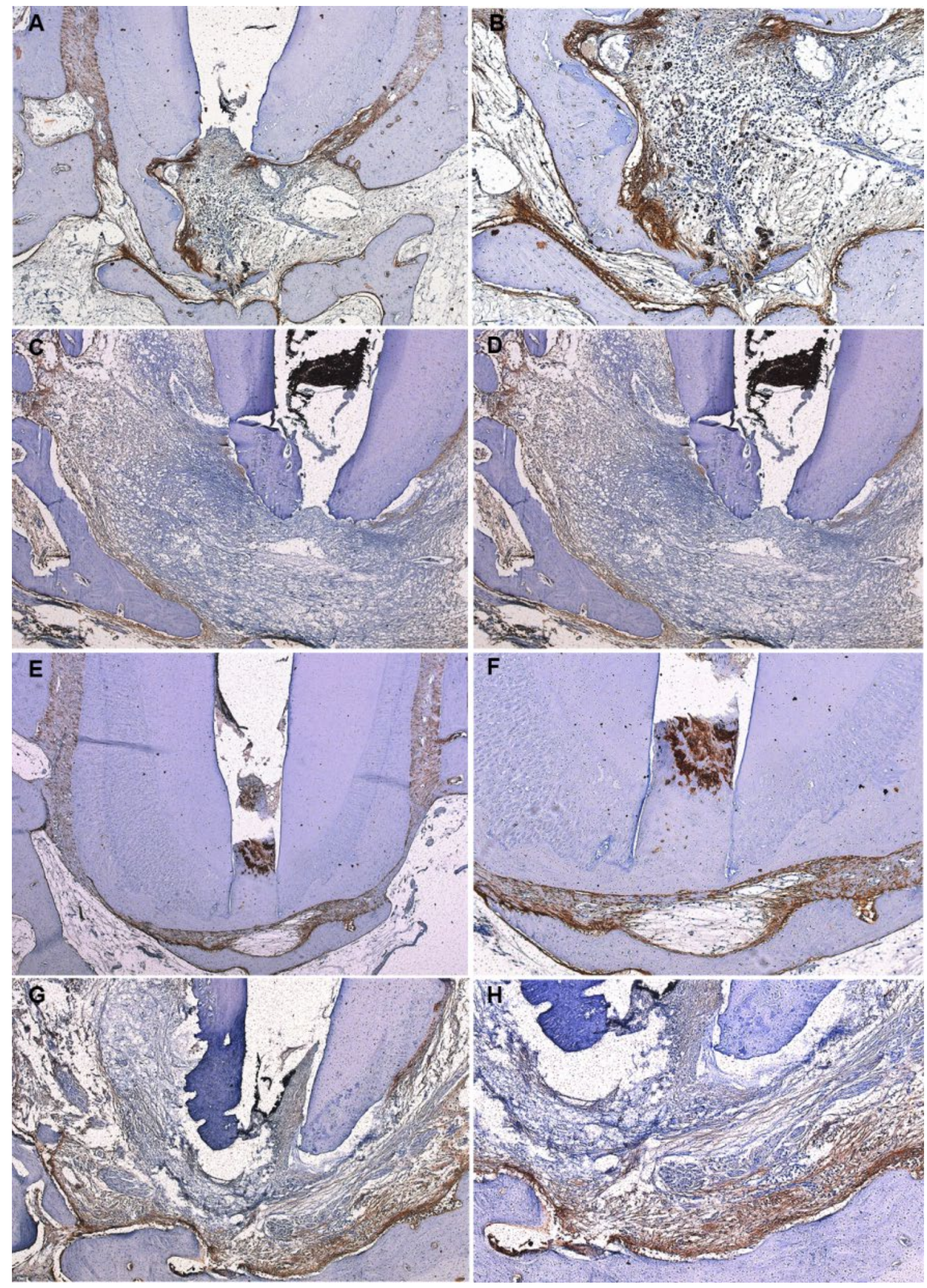



Figura 6 - Fotomicrografias representativas dos espécimes após tratamento endodôntico realizado em duas sessões, empregando um curativo de demora à base de hidróxido de cálcio $(\mathrm{CH})$, após $120(\mathrm{AB})$ e 180 dias (EF), e após tratamento endodôntico realizado em sessão única, empregando a aPDT, após 120 (CD) e 180 dias (GH), demonstrando imunomarcação para osteopontina [OPN] (marrom), que foi mais intensa nos grupos tratados com $\mathrm{CH}$

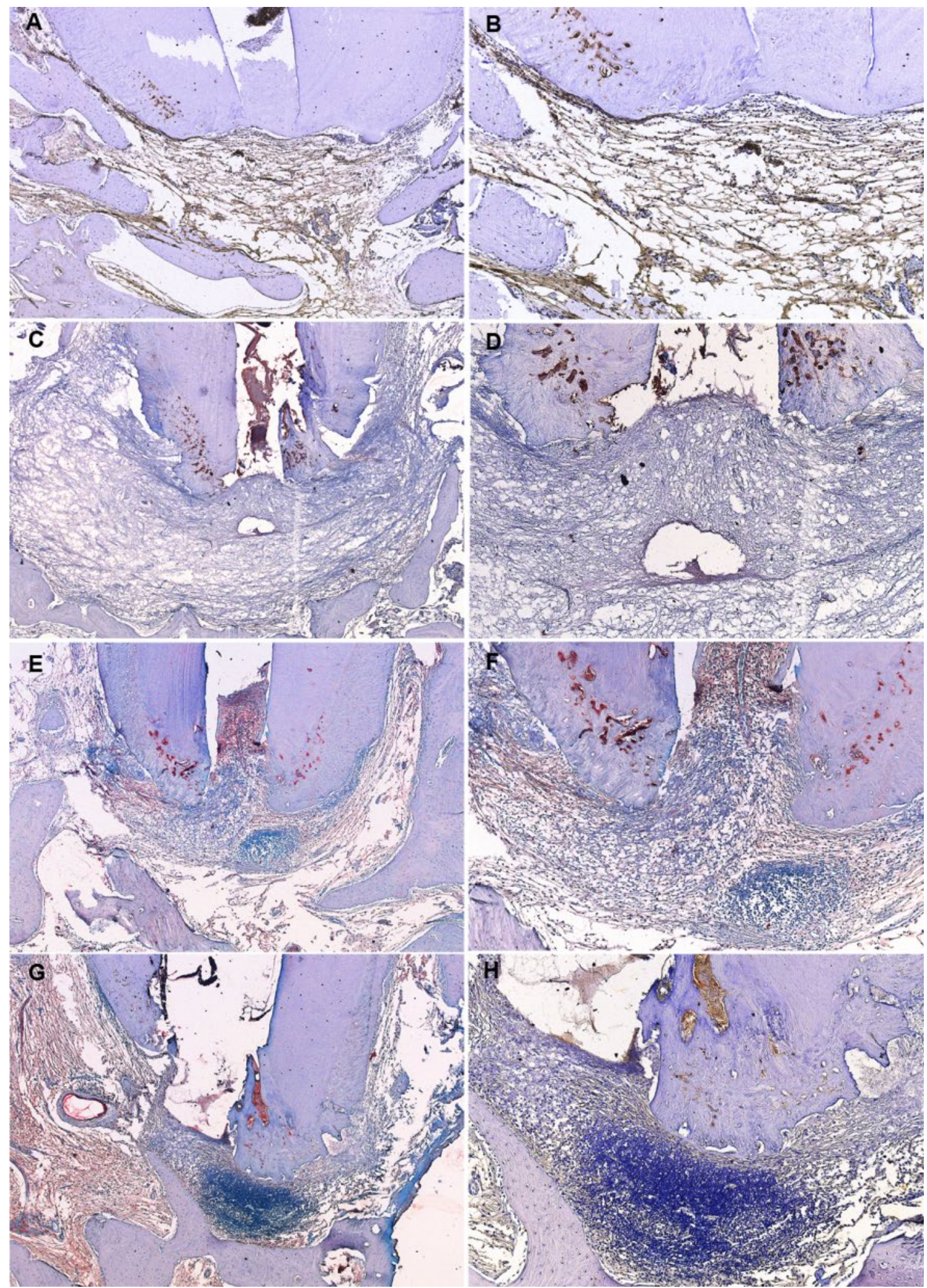



$D_{\text {iscussão }}$ 



\section{Discussão}

O presente estudo avaliou a resposta de dentes de cães com lesão periapical ao tratamento endodôntico realizado em sessão única, empregando a aPDT ou ao tratamento endodôntico realizado em duas sessões, empregando um curativo de demora à base de hidróxido de cálcio. Os grupos que foram tratados em duas sessões e receberam a medicação intracanal apresentaram os melhores resultados.

O mecanismo de ação pelo qual o hidróxido de cálcio induz o reparo tecidual é bem conhecido (Desai e Chandler, 2009). O hidróxido de cálcio é quimicamente classificado como uma base forte, apresentando alto pH. A dissociação iônica em íons $\mathrm{Ca}^{2+}$ e $\mathrm{OH}^{-}$é a responsável por suas principais propriedades, como o efeito antimicrobiano e a indução de deposição de tecido mineralizado (Mohammadi e Dummer, 2011). Alguns estudos in vivo demonstraram a alta eficácia do hidróxido de cálcio contra bactérias endodônticas (Vera et al., 2012; Silva et al., 2017). Além disso, a pasta utilizada como medicação intracanal à base de hidróxido de cálcio é bem tolerada pelos tecidos ósseos e pela polpa dentária e tem sido o material de escolha para a indução da formação apical de tecido mineralizado em dentes necrosados (Schroder, 1985; Leonardo et al., 2006; Da Silva et al., 2008; Silva et al., 2010; Mohammadi e Dummer, 2011; Nowicka et al., 2015; Hidalgo et al., 2016; Silva et al., 2017; Didilescu et al., 2018). Portanto, no presente estudo, o tratamento endodôntico com curativo de demora à base de hidróxido de cálcio foi considerado como controle, uma vez que esse protocolo é bem estabelecido, proporcionando maiores taxas de sucesso e promovendo o reparo apical e periapical, em estudos histopatológicos (Silva et al., 2010; Borsatto et al., 2016; Hidalgo et al., 2016).

Os resultados histopatológicos do presente estudo indicaram o reparo tecidual nos grupos que receberam curativo com hidróxido de cálcio e foram confirmados pela análise morfométrica da área das lesões periapicais. Os dentes dos grupos tratados com a pasta à base de hidróxido de cálcio apresentaram lesões significativamente menores, em comparação aos tratados com a aPDT, após 120 e 180 dias. Esses resultados estão de acordo com estudos prévios que também demonstraram lesões periapicais menores nos grupos medicados com pasta à base 
de hidróxido de cálcio, após 90 (Borsatto et al., 2016), 120 e 180 dias (Hidalgo et al., 2016).

Embora alguns estudos in vitro tenham demonstrado uma elevada atividade antimicrobiana da aPDT contra patógenos endodônticos (Kranz et al., 2011; Prażmo et al., 2017) e alguns estudos in vivo tenham demonstrado a eficácia do hidróxido de cálcio e da aPDT contra bactérias endodônticas (Trindade et al., 2017; Ahangari et al., 2017), as avaliações histopatológicas prévias ainda não são consistentes em recomendar o uso da aPDT em substituição ao tratamento convencional realizado em sessões múltiplas (Borsatto et al., 2016; Hidalgo et al., 2016), corroborando com os resultados obtidos no presente estudo. Portanto, com base nos dados existentes na literatura e nos resultados do presente estudo, os parâmetros para o uso seguro da aPDT na prática clínica precisam ser melhor estabelecidos e investigados.

Estudos prévios realizados por nosso grupo de pesquisa (Silva et al., 2012; Borsatto et al., 2016) avaliaram a resposta dos tecidos apicais e periapicais, por meio de avaliação histopatológica, após o uso da aPDT em períodos mais curtos (90 dias ou menos) e hipotetizaram que o reparo tecidual da região periapical poderia ser alcançado após períodos mais longos de avaliação. Com base nesses estudos, Hidalgo et al. (2016) aplicaram períodos mais longos (120 e 180 dias) de avaliação e demonstraram que o tratamento com curativo de demora intracanal à base hidróxido de cálcio, entre as sessões, proporcionou maiores taxas de sucesso, em comparação ao tratamento realizado em sessão única e suplementado com a aPDT, mesmo após períodos mais longos de avaliação, da mesma forma que o observado no presente estudo.

Adicionalmente, diferentemente dos estudos prévios que também avaliaram a aPDT no reparo de lesões periapicais in vivo, o presente estudo teve como objetivo estudar os mecanismos de ação envolvidos no reparo periapical, após o tratamento endodôntico realizado em sessão única e suplementado com o uso da aPDT, em comparação ao tratamento realizado em duas sessões, com o uso do curativo de demora à base de hidróxido de cálcio. Assim, foram avaliados alguns mediadores da formação óssea (ALP e OPN), 120 e 180 dias após a realização dos tratamentos. Ambos os tratamentos induziram a expressão desses mediadores, porém, com maior intensidade nos grupos tratados com pasta à base de hidróxido de cálcio. 
Sabe-se que a ALP é utilizada como marcador da atividade osteoblástica, sendo considerada como o mais comum indicador da formação óssea (Schmidt-Gayk et al., 1995). Por outro lado, a OPN está relacionada a um estágio mais tardio durante a diferenciação osteoblástica (Rodan e Noda, 1991) e apresenta um efeito protetor nas infecções endodônticas (Rittling et al., 2010). O efeito da aPDT sobre esses marcadores foi previamente avaliado em associação ao tratamento periodontal, em pacientes com periodontite crônica. Os níveis de mRNA para diversos marcadores ósseos, incluindo a ALP e a OPN, foram investigados e 0 tratamento com a aPDT não foi capaz de aumentar a expressão desses marcadores nos tecidos periodontais, após o tratamento periodontal cirúrgico (Andrade et al., 2013). No entanto, não há estudos na literatura específica avaliando a expressão de ALP e OPN em dentes com lesão periapical após o tratamento endodôntico associado ao uso da aPDT, o que impossibilita uma comparação direta dos nossos achados com estudos prévios.

Além disso, sabe-se que a angiogênese é fundamental para que ocorra a formação de novos tecidos no processo de reparo, permitindo que as células recebam os nutrientes necessários para sua proliferação e diferenciação (Nabeshima et al., 2018). Portanto, a formação de vasos sanguíneos tem sido associada a um reparo tecidual mais avançado, em modelos experimentais in vivo (Matos et al., 2018). Borsatto et al. (2016), em análise qualitativa de lesões periapicais tratadas com curativo à base de hidróxido de cálcio ou com aPDT, demonstraram que o hidróxido de cálcio induziu maior proliferação de vasos sanguíneos, corroborando com o presente estudo que confirmou esse achado de maneira quantitativa.

De acordo com uma revisão sistemática (Chrepa et al., 2014), as informações disponíveis na literatura sobre a aplicação clínica da aPDT na desinfecção de canais radiculares, durante o tratamento endodôntico, são limitadas. Os estudos existentes demonstraram um efeito positivo dessa terapia na redução dos níveis de micro-organismos presentes nos canais radiculares. No entanto, sabe-se que a aPDT promove alguns efeitos nocivos para as células e a dimensão do dano celular depende de alguns parâmetros que devem ser melhor estabelecidos, previamente à sua indicação clínica. 
O presente estudo aplicou um sistema específico para o uso da aPDT na Endodontia, utilizando um laser tridimensional, por meio de uma ponta de fibra óptica flexível em toda a extensão dos canais radiculares. Estes foram previamente condicionados com um fotossensibilizador à base de fenotiazina, na concentração de $10 \mathrm{mg} / \mathrm{mL}$, em um sistema específico para o uso no sistema de canais radiculares (Helbo Blue). Embora a aPDT tenha estimulado a expressão de marcadores da formação óssea nas regiões apical e periapical, os resultados obtidos foram inferiores aos obtidos após o tratamento endodôntico realizado em duas sessões e o uso do curativo de demora à base de hidróxido de cálcio. Portanto, estudos adicionais devem ser conduzidos para estabelecer parâmetros mais adequados que permitam a indicação e o uso seguro da aPDT no tratamento endodôntico de dentes com necrose pulpar e lesão periapical. 
Conclusão 



\section{CONCLUSÃo}

Embora o tratamento endodôntico realizado em sessão única empregando a aPDT tenha estimulado a angiogênese e a expressão de marcadores da formação óssea nas regiões apical e periapical, o tratamento endodôntico realizado em duas sessões empregando um curativo de demora à base de hidróxido de cálcio os estimulou mais intensamente e promoveu melhor reparo das lesões periapicais, em dentes de cães. 

$R_{\text {EFEREANCIAS }}$ 



\section{ReferênCIAS}

1. Adl A, Hamedi S, Sedigh Shams M, Motamedifar M, Sobhnamayan F. The ability of triple antibiotic paste and calcium hydroxide in disinfection of dentinal tubules. Iran Endod J. 2014;9(2):123-6.

2. Adl A, Motamedifar M, Shams MS, Mirzaie A. Clinical investigation of the effect of calcium hydroxide intracanal dressing on bacterial lipopolysaccharide reduction from infected root canals. Aust Endod J. 2015;41(1):12-6.

3. Adl A, Shojaee NS, Motamedifar M. A Comparison between the Antimicrobial Effects of Triple Antibiotic Paste and Calcium Hydroxide Against Entrococcus Faecalis. Iran Endod J. 2012;7(3):149-55.

4. Andolfatto $C$, da Silva GF, Cornélio AL, Guerreiro-Tanomaru JM, Tanomaru-Filho M, Faria G, Bonetti-Filho I, Cerri PS. Biocompatibility of intracanal medications based on calcium hydroxide. ISRN Dent. 2012;2012:904963.

5. Andersen M, Lund A, Andreasen JO, Andreasen FM. In vitro solubility of human pulp tissue in calcium hydroxide and sodium hypochlorite. Endod Dent Traumatol. 1992;8(3):104-8.

6. Andrade PF, Garlet GP, Silva JS, Fernandes PG, Milanezi C, Novaes AB Jr, Palioto DB, Grisi MF, Taba M Jr, Souza SL. Adjunct effect of the antimicrobial photodynamic therapy to an association of non-surgical and surgical periodontal treatment in modulation of gene expression: a human study. J Photochem Photobiol B. 2013;126:119-25.

7. Ahangari Z, Mojtahed Bidabadi M, Asnaashari M, Rahmati A, Tabatabaei FS. Comparison of the Antimicrobial Efficacy of Calcium Hydroxide and Photodynamic Therapy Against Enterococcus faecalis and Candida albicans in Teeth With Periapical Lesions; An In Vivo Study. J Lasers Med Sci 2017;8(2):7278.

8. Ahmad IA, Alenezi MA. Root and Root Canal Morphology of Maxillary First Premolars: A Literature Review and Clinical Considerations. J Endod. 2016;42(6):861-72.

9. Ahmed HM, Hashem AA. Accessory roots and root canals in human anterior teeth: a review and clinical considerations. Int Endod J. 2016;49(8):724-36.

10. Allard U, Stromberg U, Stromberg T. Endodontic treatment of experimentally induced apical periodontitis in dogs. Endod Dent Traumatol. 1987;3(5):240-4.

11. Andrade PF, Garlet GP, Silva JS, Fernandes PG, Milanezi C, Novaes AB, Jr., et al. Adjunct effect of the antimicrobial photodynamic therapy to an association of non-surgical and surgical periodontal treatment in modulation of gene expression: a human study. J Photochem Photobiol B 2013;126:119-125. 
12. Arruda MEF, Neves MAS, Diogenes A, Mdala I, Guilherme BPS, Siqueira JF Jr, Rôças IN. Infection Control in Teeth with Apical Periodontitis Using a Triple Antibiotic Solution or Calcium Hydroxide with Chlorhexidine: A Randomized Clinical Trial. J Endod. 2018;44(10):1474-1479.

13. Barthel CR, Levin LG, Reisner HM, Trope M. TNF-alpha release in monocytes after exposure to calcium hydroxide treated Escherichia coli LPS. Int Endod J. 1997;30(3):155-9.

14. Bharuka SB, Mandroli PS. Single- versus two-visit pulpectomy treatment in primary teeth with apical periodontitis: A double-blind, parallel group, randomized controlled trial. J Indian Soc Pedod Prev Dent. 2016 OctDec;34(4):383-90.

15. Borsatto MC, Correa-Afonso AM, Lucisano MP, Bezerra da Silva RA, Paula-Silva FW, Nelson-Filho $P$, et al. One-session root canal treatment with antimicrobial photodynamic therapy (aPDT): an in vivo study. Int Endod J 2016;49(6):511518.

16. Carrera ET, Dias HB, Corbi SCT, Marcantonio RAC, Bernardi ACA, Bagnato VS, Hamblin MR, Rastelli ANS. The application of antimicrobial photodynamic therapy (aPDT) in dentistry: a critical review. Laser Phys. 2016 Dec;26(12).

17. Chhabra A, Dogra A, Garg N, Bhatia R, Sharma S, Thakur S. Clinical and radiographic assessment of periapical pathology in single versus multivisit root canal treatment: An in vivo study. J Conserv Dent 2017;20(6):429-433.

18. Chiniforush N, Pourhajibagher M, Shahabi S, Kosarieh E, Bahador A. Can Antimicrobial Photodynamic Therapy (aPDT) Enhance the Endodontic Treatment? J Lasers Med Sci. 2016;7(2):76-85.

19. Chrepa V, Kotsakis GA, Pagonis TC, Hargreaves KM. The effect of photodynamic therapy in root canal disinfection: a systematic review. J Endod 2014;40(7):891-898.

20. Cieplik F, Tabenski L, Buchalla W, Maisch T. Antimicrobial photodynamic therapy for inactivation of biofilms formed by oral key pathogens. Front Microbiol. 2014 Aug 12;5:405.

21. Cintra LTA, Benetti $F$, de Azevedo Queiroz ÍO, Ferreira LL, Massunari $L$, Bueno CRE, de Oliveira SHP, Gomes-Filho JE. Evaluation of the Cytotoxicity and Biocompatibility of New Resin Epoxy-based Endodontic Sealer Containing Calcium Hydroxide. J Endod. 2017;43(12):2088-2092.

22. Cohenca N, Romualdo PC, da Silva LAB, da Silva RAB, de Queiroz AM, De Rossi $A$, et al. Tissue response to root canal irrigation systems in dogs' teeth with apical periodontitis. Clin Oral Investig. 2015;19(5):1147-56. 
23. Cohenca N, Silva LAB, Silva RAB, Nelson-Filho P, Heilborn C, Watanabe E, et al. Microbiological evaluation of different irrigation protocols on root canal disinfection in teeth with apical periodontitis: An In Vivo Study. Braz Dent J. 2013;24:467-73.

24. Dai T, Huang YY, Hamblin MR. Photodynamic therapy for localized infections-state of the art. Photodiagnosis Photodyn Ther 2009;6(3-4):170-188.

25. De Castro Rizzi-Maia C, Maia-Filho EM, Nelson-Filho P, Segato RA, de Queiroz AM, Paula-Silva FW, et al. Single vs Two-session Root Canal Treatment: A Preliminary Randomized Clinical Study using Cone Beam Computed Tomography. J Contemp Dent Pract 2016;17(7):515-521.

26. De Oliveira BP, Aguiar CM, Camara AC. Photodynamic therapy in combating the causative microorganisms from endodontic infections. Eur J Dent 2014;8(3):424-430.

27. de Oliveira PG, Silveira E Souza AM, Novaes AB Jr, Taba M Jr, Messora MR, Palioto DB, Grisi MF, Tedesco AC, de Souza SL. Adjunctive effect of antimicrobial photodynamic therapy in induced periodontal disease. Animal study with histomorphometrical, immunohistochemical, and cytokine evaluation. Lasers Med Sci. 2016;31(7):1275-83.

28. Desai S, Chandler N. Calcium hydroxide-based root canal sealers: a review. J Endod 2009;35(4):475-480.

29. De Rossi A, Silva LA, Leonardo MR, Rocha LB, Rossi MA. Effect of rotary or manual instrumentation, with or without a calcium hydroxide/1\% chlorhexidine intracanal dressing, on the healing of experimentally induced chronic periapical lesions. Oral Surg Oral Med Oral Pathol Oral Radiol Endod. 2005;99(5):628-36.

30. Didilescu AC, Cristache CM, Andrei M, Voicu G, Perlea P. The effect of dental pulp-capping materials on hard-tissue barrier formation: A systematic review and meta-analysis. J Am Dent Assoc. 2018;149(10):903-917.e4.

31. Diogo P, Fernandes C, Caramelo F, Mota M, Miranda IM, Faustino MAF, Neves MGPMS, Uliana MP, de Oliveira KT, Santos JM, Gonçalves T. Antimicrobial Photodynamic Therapy against Endodontic Enterococcus faecalis and Candida albicans Mono and Mixed Biofilms in the Presence of Photosensitizers: A Comparative Study with Classical Endodontic Irrigants. Front Microbiol. 2017;30;8:498.

32. Donyavi Z, Ghahari P, Esmaeilzadeh M, Kharazifard M, Yousefi-Mashouf R. Antibacterial efficacy of calcium hydroxide and chlorhexidine mixture for treatment of teeth with primary endodontic lesions: a randomized clinical trial. Iran Endod J. 2016;11(4):255-60. 
33. Dorasani G, Madhusudhana K, Chinni SK. Clinical and radiographic evaluation of single-visit and multi-visit endodontic treatment of teeth with periapical pathology: An in vivo study. J Conserv Dent 2013;16(6):484-488.

34. Dougherty TJ, Gomer CJ, Henderson BW, Jori G, Kessel D, Korbelik M, Moan J, Peng Q. Photodynamic therapy. J Natl Cancer Inst. 1998 Jun 17;90(12):889905.

35. Dougherty TJ. Photodynamic therapy. Clin Chest Med. 1985 Jun;6(2):219-36.

36. Estrela $C$, Holland R, Estrela CR, Alencar AH, Sousa-Neto MD, Pecora JD. Characterization of successful root canal treatment. Braz Dent J 2014;25(1):311.

37. Eppa HR, Puppala R, Kethineni B, Banavath S, Kanumuri PK, Kishore GVS. Comparative Evaluation of Three Different Materials: Mineral Trioxide Aggregate, Triple Antibiotic Paste, and Abscess Remedy on Apical Development of Vital Young Permanent Teeth. Contemp Clin Dent. 2018;9(2):158-163.

38. Eyuboglu TF, Olcay K, Ozcan M. A clinical study on single-visit root canal retreatments on consecutive 173 patients: frequency of periapical complications and clinical success rate. Clin Oral Investig. 2017;21(5):1761-8.

39. Fekrazad R, Seraj B, Chiniforush N, Rokouei M, Mousavi N, Ghadimi S. Effect of antimicrobial photodynamic therapy on the counts of salivary Streptococcus mutans in children with severe early childhood caries. Photodiagnosis Photodyn Ther. 2017 Jun;18:319-322.

40. Ferreira, DCA. Desenvolvimento e caracterização físico-química de um sistema para liberação intracanal de Epigalocatequina-3-galato e seu efeito na cor dos dentes. Ribeirão Preto, 2013. 99p. [Dissertação de Mestrado]. Ribeirão Preto: Faculdade de Odontologica de Ribeirão Preto da Universidade de São Paulo; 2013.

41. Fonzar F, Mollo A, Venturi M, Pini P, Fabian Fonzar R, Trullenque-Eriksson A, Esposito M. Single versus two visits with 1-week intracanal calcium hydroxide medication for endodontic treatment: One-year post-treatment results from a multicentre randomised controlled trial. Eur J Oral Implantol. 2017;10(1):29-41.

42. Fumes AC, Romualdo PC, Monteiro RM, Watanabe E, Corona SAM, Borsatto MC. Influence of pre-irradiation time employed in antimicrobial photodynamic therapy with diode laser. Lasers Med Sci. 2018 Jan;33(1):67-73.

43. Garcez AS, Arantes-Neto JG, Sellera DP, Fregnani ER. Effects of antimicrobial photodynamic therapy and surgical endodontic treatment on the bacterial load reduction and periapical lesion healing. Three years follow up. Photodiagnosis Photodyn Ther. 2015;12(4):575-80. 
44. Gursoy H, Ozcakir-Tomruk C, Tanalp J, Yilmaz S. Photodynamic therapy in dentistry: a literature review. Clin Oral Investig. 2013;17(4):1113-25.

45. Hasselgren G, Olsson B, Cvek M. Effects of calcium hydroxide and sodium hypochlorite on the dissolution of necrotic porcine muscle tissue. J Endod. $1988 ; 14(3): 125-7$.

46. Hayek RR, Araújo NS, Gioso MA, Ferreira J, Baptista-Sobrinho CA, Yamada AM, Ribeiro MS. Comparative study between the effects of photodynamic therapy and conventional therapy on microbial reduction in ligature-induced periimplantitis in dogs. J Periodontol. 2005;76(8):1275-81.

47. Heithersay GS. Stimulation of root formation in incompletely developed pulpless teeth. Oral Surg Oral Med Oral Pathol. 1970;29(4):620-30.

48. Hidalgo LR, da Silva LA, Nelson-Filho P, da Silva RA, de Carvalho FK, Lucisano $M P$, et al. Comparison between one-session root canal treatment with aPDT and two-session treatment with calcium hydroxide-based antibacterial dressing, in dog's teeth with apical periodontitis. Lasers Med Sci 2016;31(7):1481-1491.

49. Hidalgo LRDC, Silva LABD, Leoni GB, Mazzi-Chaves JF, Carvalho EEDS, Consolaro A, Sousa-Neto MD. Mechanical Preparation Showed Superior Shaping Ability than Manual Technique in Primary Molars - A Micro-Computed Tomography Study. Braz Dent J. 2017;28(4):453-460.

50. Holland R, Gomes JEF, Cintra LTA, Queiroz IOA, Estrela C. Factors affecting the periapical healing process of endodontically treated teeth. J Appl Oral Sci 2017;25(5):465-476.

51. Hong JY, Yon J, Lee JS, Lee IK, Yang C, Kim MS, Choi SH, Jung UW. Effects of epigallocatechin-3-gallate on the healing of extraction sockets with a periapical lesion: A pilot study in dogs. J Biomed Mater Res B Appl Biomater. 2015;103(4):727-34.

52. Huang L, Dai T, Hamblin MR. Antimicrobial photodynamic inactivation and photodynamic therapy for infections. Methods Mol Biol. 2010;635:155-73.

53. Huffaker SK, Safavi K, Spangberg LS, Kaufman B. Influence of a passive sonic irrigation system on the elimination of bacteria from root canal systems: a clinical study. J Endod. 2010;36(8):1315-8.

54. Ito IY, Junior FM, Paula-Silva FW, Da Silva LA, Leonardo MR, Nelson-Filho P. Microbial culture and checkerboard DNA-DNA hybridization assessment of bacteria in root canals of primary teeth pre- and post-endodontic therapy with a calcium hydroxide/chlorhexidine paste. Int J Paediatr Dent. 2011;21(5):353-60.

55. Juric IB, Plecko V, Panduric DG, Anic I. The antimicrobial effectiveness of photodynamic therapy used as an addition to the conventional endodontic retreatment: a clinical study. Photodiagnosis Photodyn Ther 2014;11(4):549-555. 
56. Kömerik N, Curnow A, MacRobert AJ, Hopper C, Speight PM, Wilson M. Fluorescence biodistribution and photosensitising activity of toluidine blue $o$ on rat buccal mucosa. Lasers Med Sci. 2002;17:86-92.

57. Kömerik N, Nakanishi $H$, MacRobert AJ, Henderson B, Speight P, Wilson M. In vivo killing of Porphyromonas gingivalis by toluidine blue-mediated photosensitization in an animal model. Antimicrob Agents Chemother. 2003;47(3):932-40.

58. Kranz S, Guellmar A, Volpel A, Gitter B, Albrecht V, Sigusch BW. Photodynamic suppression of Enterococcus faecalis using the photosensitizer mTHPC. Lasers Surg Med 2011;43(3):241-248.

59. Lakhani AA, Sekhar KS, Gupta P, Tejolatha B, Gupta A, Kashyap S, et al. Efficacy of triple antibiotic paste, moxifloxacin, calcium hydroxide and $2 \%$ chlorhexidine gel in elimination of E. Faecalis: an in vitro study. J Clin Diagn Res. 2017;11(1):6-9.

60. Lee $\mathrm{YL}$, Hong $\mathrm{CY}$, Kok SH, Hou KL, Lin $\mathrm{YT}$, Chen MH, et al. An extract of green tea, epigallocatechin-3-gallate, reduces periapical lesions by inhibiting cysteinerich 61 expression in osteoblasts. J Endod. 2009;35(2):206-11.

61. Leonardo MR, Hernandez ME, Silva LA, Tanomaru-Filho M. Effect of a calcium hydroxide-based root canal dressing on periapical repair in dogs: a histological study. Oral Surg Oral Med Oral Pathol Oral Radiol Endod. 2006;102(5):680-5.

62. Leonardo MR, da Silva LA, Leonardo Rde T, Utrilla LS, Assed S. Histological evaluation of therapy using a calcium hydroxide dressing for teeth with incompletely formed apices and periapical lesions. J Endod. 1993;19(7):348-52.

63. Leonardo MR, Silva LAB, Filho MT, Bonifácio KC, Ito IY. In Vitro Evaluation of Antimicrobial Activity of Sealers and Pastes Used in Endodontics. J Endod. 2000;26(7):391-4.

64. Leonardo MR. Endodontia: tratamento de canais radiculares. São Paulo: Artes Médicas; 2005.

65. Lima CC, Conde Júnior AM, Rizzo MS, Moura RD, Moura MS, Lima MD, Moura LF. Biocompatibility of root filling pastes used in primary teeth. Int Endod J. 2015;48(5):405-16.

66. Maisch T, Bosl C, Szeimies RM, Lehn N, Abels C. Photodynamic effects of novel XF porphyrin derivatives on prokaryotic and eukaryotic cells. Antimicrob Agents Chemother. 2005 Apr;49(4):1542-52.

67. Marinho ACS, To TT, Darveau RP, Gomes BPFA. Detection and function of lipopolysaccharide and its purified lipid $A$ after treatment with auxiliary chemical substances and calcium hydroxide dressings used in root canal treatment. Int Endod J. 2018;51(10):1118-1129. 
68. Martins SHL, Novaes AB Jr, Taba M Jr, Palioto DB, Messora MR, Reino DM, Souza SLS. Effect of surgical periodontal treatment associated to antimicrobial photodynamic therapy on chronic periodontitis: A randomized controlled clinical trial. J Clin Periodontol. 2017;44(7):717-728.

69. Matos FS, Godolphim FJ, Albuquerque-Júnior RL, Paranhos LR, Rode SM, Carvalho CA, Ribeiro MA. Laser phototherapy induces angiogenesis in the periodontal tissue after delayed tooth replantation in rats. J Clin Exp Dent. 2018 Apr 1;10(4):e335-e340.

70. Mohammadi Z, Dummer PM. Properties and applications of calcium hydroxide in endodontics and dental traumatology. Int Endod J 2011;44(8):697-730.

71. Mohammadi $Z$, Jafarzadeh $H$, Shalavi S, Palazzi F. Recent Advances in Root Canal Disinfection: A Review. Iran Endod J 2017;12(4):402-406.

72. Moreira MS, Anuar ASN, Tedesco TK, Dos Santos M, Morimoto S. Endodontic Treatment in Single and Multiple Visits: An Overview of Systematic Reviews. J Endod 2017;43(6):864-870.

73. Nabeshima CK, Valdivia JE, Caballero-Flores H, Arana-Chavez VE, Machado MEL. Immunohistological study of the effect of vascular Endothelial Growth Factor on the angiogenesis of mature root canals in rat molars. J Appl Oral Sci. 2018;26:e20170437.

74. Nelson Filho P, Silva LA, Leonardo MR, Utrilla LS, Figueiredo F. Connective tissue responses to calcium hydroxide-based root canal medicaments. Int Endod J. 1999;32(4):303-11.

75. Novaes AB Jr, Schwartz-Filho HO, de Oliveira RR, Feres M, Sato S, Figueiredo LC. Antimicrobial photodynamic therapy in the non-surgical treatment of aggressive periodontitis: microbiological profile. Lasers Med Sci. 2012;27(2):389-95.

76. Novaes $A B$ Jr, Schwartz-Filho HO, de Oliveira RR, Feres M, Sato S, Figueiredo LC. Antimicrobial photodynamic therapy in the non-surgical treatment of aggressive periodontitis: microbiological profile. Lasers Med Sci. 2012 Mar;27(2):389-95.

77. Nowicka A, Wilk G, Lipski M, Kołecki J, Buczkowska-Radlińska J. Tomographic Evaluation of Reparative Dentin Formation after Direct Pulp Capping with $\mathrm{Ca}(\mathrm{OH}) 2$, MTA, Biodentine, and Dentin Bonding System in Human Teeth. J Endod. 2015;41(8):1234-40.

78. Oliveira, DSB. PDT: Fotossensibilizadores e Tempos de Exposição a Luz não inluenciaram na Resposta Tecidual de Camundongos Isogênicos. Ribeirão Preto. [Tese de Doutorado]. Ribeirão Preto: Faculdade de Odontologica de Ribeirão Preto da Universidade de São Paulo; 2016, 115p. 
79. Oliveira LD, Jorge AO, Carvalho CA, Koga-Ito CY, Valera MC. In vitro effects of endodontic irrigants on endotoxins in root canals. Oral Surg Oral Med Oral Pathol Oral Radiol Endod. 2007;104(1):135-42.

80. Oliveira LD, Leao MV, Carvalho CA, Camargo CH, Valera MC, Jorge AO, et al. In vitro effects of calcium hydroxide and polymyxin $B$ on endotoxins in root canals. J Dent. 2005;33(2):107-14.

81. Pai S, Vivekananda Pai AR, Thomas MS, Bhat V. Effect of calcium hydroxide and triple antibiotic paste as intracanal medicaments on the incidence of interappointment flare-up in diabetic patients: An in vivo study. J Conserv Dent. 2014;17(3):208-11.

82. Paiva SS, Siqueira JF, Jr., Rocas IN, Carmo FL, Leite DC, Ferreira DC, et al. Molecular microbiological evaluation of passive ultrasonic activation as a supplementary disinfecting step: a clinical study. J Endod. 2013;39(2):190-4.

83. Pawar R, Alqaied A, Safavi K, Boyko J, Kaufman B. Influence of an apical negative pressure irrigation system on bacterial elimination during endodontic therapy: a prospective randomized clinical study. J Endod. 2012;38(9):1177-81.

84. Peters OA. Current challenges and concepts in the preparation of root canal systems: a review. J Endod 2004;30(8):559-567.

85. Prazmo EJ, Godlewska RA, Mielczarek AB. Effectiveness of repeated photodynamic therapy in the elimination of intracanal Enterococcus faecalis biofilm: an in vitro study. Lasers Med Sci 2017;32(3):655-661.

86. Profio $A E$, Doiron $D R$. Transport of light in tissue in photodynamic therapy. Photochem Photobiol. 1987; 46:591-599.

87. Pucinelli $C M$, Silva LABD, Cohenca N, Romualdo PC, Silva RABD, Consolaro A, Queiroz AM, Nelson P Filho. Apical Negative Pressure irrigation presents tissue compatibility in immature teeth. J Appl Oral Sci. 2017;25(6):612-619.

88. Queiroz AC, Suaid FA, de Andrade PF, Oliveira FS, Novaes AB Jr, Taba M Jr, Palioto DB, Grisi MF, Souza SL. Adjunctive effect of antimicrobial photodynamic therapy to nonsurgical periodontal treatment in smokers: a randomized clinical trial. Lasers Med Sci. 2015;30(2):617-25.

89. Raghavendra M, Koregol A, Bhola S. Photodynamic therapy: a targeted therapy in periodontics. Aust Dent J. 2009 Sep;54 Suppl 1:S102-9.

90. Ramezanali F, Samimi S, Kharazifard M, Afkhami $F$. The in vitro antibacterial efficacy of persian green tea extract as an intracanal irrigant on enterococcus faecalis biofilm. Iran Endod J. 2016;11(4):304-8.

91. Ramos UD, Ayub LG, Reino DM, Grisi MF, Taba M Jr, Souza SL, Palioto DB, Novaes $A B$ Jr. Antimicrobial photodynamic therapy as an alternative to systemic antibiotics: results from a double-blind, randomized, placebo-controlled, clinical study on type 2 diabetics. J Clin Periodontol. 2016;43(2):147-55. 
92. Rittling SR, Zetterberg C, Yagiz K, Skinner S, Suzuki N, Fujimura A, et al. Protective role of osteopontin in endodontic infection. Immunology 2010;129(1):105-114.

93. Rodan GA, Noda M. Gene expression in osteoblastic cells. Crit Rev Eukaryot Gene Expr 1991;1(2):85-98.

94. Safavi KE, Nichols FC. Alteration of biological properties of bacterial lipopolysaccharide by calcium hydroxide treatment. J Endod. 1994;20(3):127-9.

95. Sangalli J, Júnior EGJ, Bueno CRE, Jacinto RC, Sivieri-Araújo G, Filho JEG, Cintra LTÂ, Junior ED. Antimicrobial activity of Psidium cattleianum associated with calcium hydroxide against Enterococcus faecalis and Candida albicans: an in vitro study. Clin Oral Investig. 2018;22(6):2273-2279.

96. Schmidt-Gayk H, Roth $H J$, Becker $S$, Reichel $H$, Boneth HG, Knuth UA. Noninvasive parameters of bone metabolism. Curr Opin Nephrol Hypertens 1995;4(4):334-338.

97. Schröder U. Effects of calcium hydroxide-containing pulp-capping agents on pulp cell migration, proliferation, and differentiation. J Dent Res. 1985 Apr;64 Spec No:541-8.

98. Silva RA, Assed S, Nelson-Filho P, Silva LA, Consolaro A. Subcutaneous tissue response of isogenic mice to calcium hydroxide-based pastes with chlorhexidine. Braz Dent J. 2009;20:99-106.

99. Silva LA, Leonardo MR, Oliveira DS, Silva RA, Queiroz AM, Hernandez PG, et al. Histopathological evaluation of root canal filling materials for primary teeth. Braz Dent J 2010;21(1):38-45.

100. Silva LAB, Nelson-Filho P, Leonardo MR, Rossi MA, Pansani CA. Effect of calcium hydroxide on bacterial endotoxin in vivo. J Endod. 2002;28(2):94-8.

101. Silva LA, Novaes AB Jr, de Oliveira RR, Nelson-Filho P, Santamaria M Jr, Silva RA. Antimicrobial photodynamic therapy for the treatment of teeth with apical periodontitis: a histopathological evaluation. J Endod 2012;38(3):360-366.

102. Silva LA, Paula-Silva FW, Leonardo MR, Assed S. Radiographic evaluation of pulpal and periapical response of dogs' teeth after pulpotomy and use of recombinant human bone morphogenetic protein-7 as a capping agent. J Dent Child. 2008;75(1):14-9.

103. Silva LA, Romualdo PC, Silva RA, Souza-Gugelmin MC, Pazelli LC, De Freitas AC, et al. Antibacterial Effect of Calcium Hydroxide With or Without Chlorhexidine as Intracanal Dressing in Primary Teeth With Apical Periodontitis. Pediatr Dent 2017;39(1):28-33.

104. Silva $L A B$, Pieroni KAMG, Nelson-Filho $P$, Silva RAB, Hernandéz-Gatón $P$, Lucisano MP, Paula-Silva FWG, de Queiroz AM. Furcation Perforation: Periradicular Tissue Response to Biodentine as a Repair Material by Histopathologic and Indirect Immunofluorescence Analyses. J Endod. 2017;43(7):1137-1142. 
105. Silva RA, Leonardo MR, da Silva LA, de Castro LM, Rosa AL, de Oliveira PT. Effects of the association between a calcium hydroxide paste and $0.4 \%$ chlorhexidine on the development of the osteogenic phenotype in vitro. J Endod. 2008;34(12):1485-9.

106. Slutzky-Goldberg I, Hanut A, Matalon S, Baev V, Slutzky H. The effect of dentin on the pulp tissue dissolution capacity of sodium hypochlorite and calcium hydroxide. J Endod. 2013;39(8):980-3.

107. Sousa EL, Martinho FC, Nascimento GG, Leite FR, Gomes BP. Quantification of endotoxins in infected root canals and acute apical abscess exudates: monitoring the effectiveness of root canal procedures in the reduction of endotoxins. J Endod. 2014;40(2):177-81.

108. Spangberg LS. Evidence-based endodontics: the one-visit treatment idea. Oral Surgery, Oral Medicine, Oral Pathology, Oral Radiology and Endodontology. 2001;6(91):617-8.

109. Tanomaru JM, Leonardo MR, Tanomaru Filho M, Bonetti Filho I, Silva LA. Effect of different irrigation solutions and calcium hydroxide on bacterial LPS. Int Endod J. 2003;36(11):733-9.

110. Takasaki AA, Aoki A, Mizutani K, Schwarz F, Sculean A, Wang CY, Koshy G, Romanos G, Ishikawa I, Izumi Y. Application of antimicrobial photodynamic therapy in periodontal and peri-implant diseases. Periodontol 2000. 2009;51:109-40.

111. Trindade AC, De Figueiredo JA, Steier L, Weber JB. Photodynamic therapy in endodontics: a literature review. Photomed Laser Surg 2015;33(3):175-182.

112. Trindade AC, de Figueiredo JAP, de Oliveira SD, Barth Junior VC, Gallo SW, Follmann C, et al. Histopathological, Microbiological, and Radiographic Analysis of Antimicrobial Photodynamic Therapy for the Treatment of Teeth with Apical Periodontitis: A Study in Rats' Molars. Photomed Laser Surg 2017;35(7):364371.

113. Türkün $M$, Cengiz $T$. The effects of sodium hypochlorite and calcium hydroxide on tissue dissolution and root canal cleanliness. Int Endod J. 1997;30(5):33542.

114. Vahabi S, Fekrazad R, Ayremlou S, Taheri S, Zangeneh N. The effect of antimicrobial photodynamic therapy with radachlorin and toluidine blue on streptococcus mutans: an in vitro study. J Dent (Tehran). 2011 Spring;8(2):4854.

115. Vera J, Siqueira JF, Jr., Ricucci D, Loghin S, Fernandez N, Flores B, et al. Oneversus two-visit endodontic treatment of teeth with apical periodontitis: a histobacteriologic study. J Endod 2012;38(8):1040-1052.

116. Wainwright M. Photodynamic antimicrobial chemotherapy (PACT). J Antimicrob Chemother. 1998 Jul;42(1):13-28.

117. Widjiastuti I, Rudyanto D, Yuanita T, Bramantoro T, Aries Widodo W. Cleaning Efficacy of Root Canal Irrigation with Positive and Negative Pressure System. Iran Endod J. 2018;13(3):398-402. 
118. Zarei M, Javidi M, Gharechahi M, Kateb M, Zare R, Kelagari ZS. Tissue reaction to different types of calcium hydroxide paste. Bull Tokyo Dent Coll. 2016;57(2):57-64.

119. Zehnder M, Grawehr M, Hasselgren G, Waltimo T. Tissue-dissolution capacity and dentin-disinfecting potential of calcium hydroxide mixed with irrigating solutions. Oral Surg Oral Med Oral Pathol Oral Radiol Endod. 2003;96(5):60813. 
Anexo 



\section{ANEXO A}

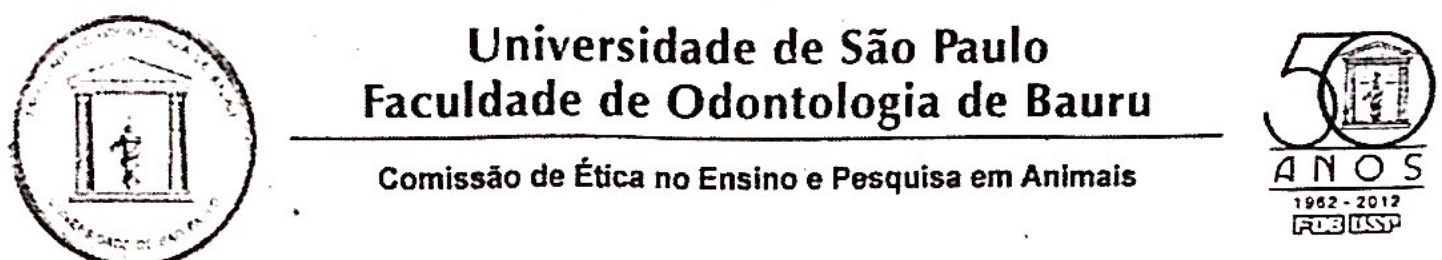

CEEPA-Proc. NP 19/2012

Bauru, 24 de setembro de 2012

Senhor Professor,

O projeto de pesquisa encaminhado a esta Comissão de Ética no Ensino e Pesquisa em Animais, denominado Terapia fotodinàmica antimicrobiana no tratamento da periodontite periapical induzida experimentalmente, de autoria de Léa Assed Bezerra da Silva e Arthur Belém de Novaes Jr., Paulo Nelson Filho, Raquel Assed Bezerra da Silva e Lidia Regina da Costa Hidalgo, foi enviado ao relator para avaliaçăo e considerado APROVADO "ad referendum" desta Comissão, nesta data.

Atenciosamente,

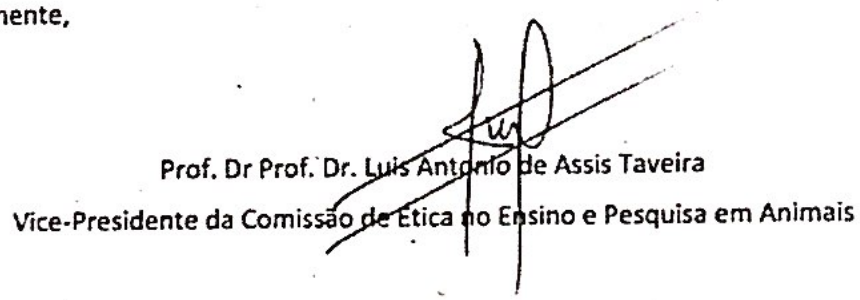

Prof: Drz Lea Assed Bezerra da Silva

Docente do Departamento de Clinica Infantil, Odontologia Preventiva e Social - FMRP/USP

Al. Dr. Octávio Pinheiro Brisolla, 9-75 - Bauru-SP - CEP 17012.101 - C.P. 73

enail mterranefob usp br - FonefFAX (Oxx 14) 3235-8356

nitto / / wrum fob usp be 